NBER WORKING PAPER SERIES

\title{
CHARACTERIZATION, EXISTENCE, AND PARETO OPTIMALITY \\ IN MARKETS WITH ASYMMETRIC INFORMATION AND ENDOGENOUS \\ AND ASYMMETRIC DISCLOSURES: \\ BASIC ANALYTICS OF REVISITING ROTHSCHILD-STIGLITZ
}

\author{
Joseph E. Stiglitz \\ Jungyoll Yun \\ Andrew Kosenko \\ Working Paper 26251 \\ http://www.nber.org/papers/w26251 \\ NATIONAL BUREAU OF ECONOMIC RESEARCH \\ 1050 Massachusetts Avenue \\ Cambridge, MA 02138 \\ September 2019
}

We are grateful to Gerry Jaynes for helpful comments on an earlier draft, to Michael Rothschild and Richard Arnott, long time collaborators on understanding insurance markets with asymmetric information, and to Byoung Heon Jun, Debarati Ghosh, Andrea Gurwitt, and Lim Nayeon for research and editorial assistance and to the Institute for New Economic Thinking and the Ford Foundation and Fulbright Foundation for financial support. The views expressed herein are those of the authors and do not necessarily reflect the views of the National Bureau of Economic Research.

NBER working papers are circulated for discussion and comment purposes. They have not been peer-reviewed or been subject to the review by the NBER Board of Directors that accompanies official NBER publications.

(C) 2019 by Joseph E. Stiglitz, Jungyoll Yun, and Andrew Kosenko. All rights reserved. Short sections of text, not to exceed two paragraphs, may be quoted without explicit permission provided that full credit, including $(\odot$ notice, is given to the source. 
Characterization, Existence, and Pareto Optimality in Markets with Asymmetric Information and Endogenous and Asymmetric Disclosures: Basic Analytics of Revisiting Rothschild-Stiglitz

Joseph E. Stiglitz, Jungyoll Yun, and Andrew Kosenko

NBER Working Paper No. 26251

September 2019

JEL No. D43,D82,D86

\begin{abstract}
We study the Rothschild-Stiglitz model of insurance markets, introducing endogenous information disclosure about insurance sales and purchases by firms and consumers. We show that a competitive equilibrium exists under unusually mild conditions, and characterize the unique equilibrium outcome. With two types of consumers the outcome is particularly simple, consisting of a pooling contract which maximizes the well-being of the low risk individual (along the zero profit pooling line) plus a supplemental (undisclosed and nonexclusive) contract that brings the high risk individual to full insurance (at his own odds). We show that this outcome is extremely robust and constrained Pareto efficient. Asymmetric equilibrium information flows with endogenous consumer disclosure are critical in supporting the equilibrium.
\end{abstract}

Joseph E. Stiglitz

Uris Hall, Columbia University

3022 Broadway, Room 212

New York, NY 10027

and NBER

jes322@ columbia.edu

Jungyoll Yun

Department of Economics,

Ewha University,

Seoul

Korea

jyyun@ewha.ac.kr
Andrew Kosenko

Marist College

School of Management

3399 North Road

Poughkeepsie, NY 12601

ak2912@columbia.edu 


\title{
Characterization, Existence, and Pareto Optimality in Markets with Asymmetric Information and Endogenous and Asymmetric Disclosures: Basic Analytics of Revisiting Rothschild-Stiglitz
}

\author{
Joseph Stiglitz, Jungyoll Yun, and Andrew Kosenko
}

\begin{abstract}
We study the Rothschild-Stiglitz model of insurance markets, introducing endogenous information disclosure about insurance sales and purchases by firms and consumers. We show that a competitive equilibrium exists under unusually mild conditions, and characterize the unique equilibrium outcome. With two types of consumers the outcome is particularly simple, consisting of a pooling contract which maximizes the well-being of the low risk individual (along the zero profit pooling line) plus a supplemental (undisclosed and nonexclusive) contract that brings the high risk individual to full insurance (at his own odds). We show that this outcome is extremely robust and constrained Pareto efficient. Asymmetric equilibrium information flows with endogenous consumer disclosure are critical in supporting the equilibrium. (JEL D43, D82, D86)
\end{abstract}

Some forty years ago, Rothschild and Stiglitz (1976) characterized equilibrium in a competitive market with exogenous information asymmetries in which market participants had full knowledge of insurance purchases. Self-selection constraints affected individual choices; but unlike the monopoly equilibrium ${ }^{1}$, no single firm framed the set of contracts among which individuals chose. There never existed a pooling equilibrium (in which the two types bought the same policy); if there existed an equilibrium, it entailed the high risk getting full insurance, and the low risk individual only getting partial

\footnotetext{
* Stiglitz: University Professor, Columbia University, Uris Hall, Room 212, 3022 Broadway, New York, NY 10027 (email: jes322@columbia.edu, cc: cao2140@columbia.edu); Stiglitz is the corresponding author. Yun: Professor, Department of Economics, Ewha University, Seoul, Korea (email: jyyun@ewha.ac.kr). Kosenko: Assistant Professor, Department of Economics, Marist College (email: kosenko.andrew@gmail.com). We are grateful to Gerry Jaynes for helpful comments on an earlier draft, to Michael Rothschild and Richard Arnott, long time collaborators on understanding insurance markets with asymmetric information, and to Byoung Heon Jun, Debarati Ghosh, Andrea Gurwitt, and Lim Nayeon for research and editorial assistance and to the Institute for New Economic Thinking and the Ford Foundation and Fulbright Foundation for financial support. This work is a shortened version of the companion paper "Characterization, Existence, and Pareto Optimality in Insurance Markets with Asymmetric Information with Endogenous and Asymmetric Disclosures; Revisiting Rothschild-Stiglitz" (Stiglitz et al 2018) which contains more results.
}

${ }^{1}$ Stiglitz (1977). 
insurance; and under plausible conditions-e.g. if the two types were not too different-what they defined as a competitive equilibrium did not exist. ${ }^{2}$ The paper was disquieting in its results: in reality equilibrium seemed to exist, and often entailed pooling, and was unsatisfactory in that even its limited existence proof relied on a special property, called the single crossing property, whereby the indifference curve of the high risk individual could cross that of the low risk individual only once. ${ }^{3}$

Since their work, there has emerged a huge literature applying the model to labor, capital, and product markets in a variety of contexts, a large number of empirical applications, and a small literature trying to repair the deficiencies in the underlying framework by formalizing the insurance "game", by changing the information/disclosure assumptions, and by changing the equilibrium concept.

This paper takes an approach that differs fundamentally from this earlier literature by endogenizing the disclosure of information about insurance purchases: each firm and consumer make a decision about what information to disclose to whom-thus information about contract purchases is not only endogenous but potentially asymmetric. The results were somewhat surprising even to us: (i) asymmetries in information about insurance purchases, especially associated with out of equilibrium moves, do indeed turn out to be important; (ii) there always exists an equilibrium, even when the single crossing property is not satisfied; and (iii) the equilibrium always entails a pooling contract. Indeed, the unique insurance allocation (an insurance allocation describes the sum of benefits and premia for each individual) consists of the pooling allocation which maximizes the well-being of the low risk individual subject to the zero-profit constraint plus a supplemental contract that brings the high risk individual to full insurance at his own odds. While the equilibrium allocation is unique, it can be supported by alternative information disclosure strategies.

We begin the analysis by characterizing the set of constrained Pareto efficient (CPE) allocations in the presence of a possibly secret contract. We then show that the CPE allocation which maximizes the well-being of the low risk individual is the unique equilibrium allocation and can be supported by simple information disclosure strategies.

While the analysis is complex, it is built upon a number of steps, each of which itself is relatively simple. As in Rothschild and Stiglitz (1976), henceforth referred to simply as RS, insurance firms offer insurance contracts, but now they may or may not decide to reveal information (all or partial) about

\footnotetext{
${ }^{2}$ Subsequent research reformulating the model in game theoretic terms showed that no pure strategy equilibrium existed. See Dasgupta and Maskin, 1986.

${ }^{3}$ As innocuous as it might seem, it won't be satisfied if the high and low risk individuals differ in their risk aversion; and with multi-crossings, equilibrium, if it exists, can look markedly different. Much of the related literature in the field employed an analogous assumption. See, e.g. Mirrlees (1971) and Spence (1973).
} 
insurance purchases to other firms. In RS, it was assumed that contracts were exclusive, e.g. implicitly, that if a firm discovered a purchaser had violated the exclusivity restriction, the coverage would be cancelled. Here, we consider a broader range of possible restrictions. Obviously, the enforceability of any conditions imposed is dependent on information available to the insurance firm. Consumers, too, have a slightly more complicated life than in RS: they have to decide which policies to buy, aware of the restrictions in place and the information that the insurance firm may have to enforce those restrictions. And they also have to decide on what information to reveal to whom.

As in RS, a competitive equilibrium is described by a set of insurance contracts, such that no one can offer an alternative contract or set of contracts and make money. Here, though, a contract is defined not just by the benefit and the premium, but also by the restrictions associated with the contract and the firm's disclosure policy.

The intuition behind our results is simple. In RS, a pooling equilibrium can always be broken by a "deviant" policy which will be purchased only by low risk individuals, and as a result, is profitable. But that deviant contract will be purchased only by low risk individuals because the deviant firm can enforce exclusivity. If high risk individuals can supplement the deviant contract breaking the putative pooling equilibrium with (secret) insurance at their own odds, that policy will be purchased by high risk individuals, and thus make a loss. The "trick" is to find an information disclosure strategy which ensures that a deviant firm can't enforce exclusivity, but which ensures that the firms selling insurance at the pooling odds (which we refer to as the "established firms") don't "oversell," i.e. high risk individuals would like to buy more insurance at the pooling odds than the low risk individuals, so there has to be information disclosure among the established firms to prevent the high risk individuals from doing so. Thus, supporting the equilibrium allocation requires asymmetries in information disclosure. But firms by themselves would have no basis for such asymmetric disclosures: without further information, they only know whether they themselves have sold insurance to an individual. ${ }^{4}$ This is where consumer disclosure becomes critical. If consumers disclose their purchases, then firms may have the basis for asymmetric disclosures. The presence of consumer disclosure is an essential feature distinguishing our paper from other work in this area. The equilibrium firm information disclosure strategy that we analyze induces truth-telling by

\footnotetext{
${ }^{4}$ This is essentially the point that Hellwig (1988) makes in criticism of Jaynes (1978) argument that with endogenous information, there always exists an equilibrium. In contrast, he shows that "there does not exist a sequential equilibrium..." He shows that Jaynes' equilibrium requires that each firm's communication strategy be conditioned on the set of contracts that are offered by other firms, making the equilibrium a reactive equilibrium, like that of Wilson, not a competitive equilibrium as in RS.
} 
consumers to established (non-deviant) firms, and this in turn enables asymmetries in firm disclosures of information about insurance purchases.

The paper is divided into 11 sections. In the first, we set out the standard insurance model. In the second we briefly recall why RS resorted to exclusive contracts, showing that with (non-loss making) secret contracts there never exists an equilibrium. Section 3 shows that if there is a non-disclosed contract (at the odds of the high risk individual), the constrained Pareto efficient contracts are always of a simple form: a pooling part (purchased by everybody), plus supplemental insurance purchased only by high risk individuals. Section 4 defines the competitive equilibrium, noting that in this context with endogenous information, insurance contracts consist not only of a benefit and a premium (as in the standard model), but also a set of restrictions to which any purchaser has to comply when purchasing a contract, and an information disclosure policy. It illustrates this with a particular set of contracts. Section 5 shows that regardless of the strategies pursued by firms and consumers, if there is a competitive equilibrium, the allocation must be the constrained Pareto efficient allocation which maximizes the wellbeing of the low risk individual. Section 6 then shows that the particular set of contracts described in section 4 supports the equilibrium allocation described in section 5 . Section 7 shows how the equilibrium construct can be extended to multiple types of individuals. Section 8 discussions some key features of equilibrium, including the lack of uniqueness and that existence does not require the single crossing property to be satisfied. Sections 9 and 10 relate our results to earlier literature. In particular, section 10 considers the standard adverse selection price equilibrium. We show how our analysis implies that in general a price equilibrium does not exist if there can exist a (non-loss making) insurance contract the purchase of which is not disclosed. Section 11 presents some concluding comments.

\section{The Model}

We employ the standard insurance model with adverse selection. An individual, indexed by $i$ ( $\epsilon$ $[0,1])$, is faced with the risk of an accident. The two types of individuals - high risk $(\mathrm{t}=\mathrm{H})$ and low-risk $(\mathrm{t}=\mathrm{L})$ - differ from each other only in the probability of accident, $\mathrm{P}_{\mathrm{t}}$. The type is privately known to the individual, while the portion $\theta$ of high-risk types is common knowledge. The average probability of accident for an individual is $\bar{P}$, where

$$
\bar{P} \equiv \theta P_{H}+(1-\theta) P_{L}
$$

An accident involves damages. The cost of repairing the damage in full is $d$. An insurance firm pays a part of the repair cost, $\alpha \leq \mathrm{d}$. The benefit is paid in the event of accident, whereas the insurer is paid insurance 
premium $\beta$ when no accident occurs. ${ }^{5}$ The price of insurance, $q$, is defined by $\frac{\beta}{\alpha}$. (In market equilibrium, the amount of insurance that an individual can buy may be limited.) The expected utility for an individual with a policy $(\alpha, \beta)$ is

$$
\mathrm{V}_{\mathrm{t}}(\alpha, \beta)=\mathrm{P}_{t} \mathrm{U}(\mathrm{w}-\mathrm{d}+\alpha)+\left(1-\mathrm{P}_{\mathrm{t}}\right) \mathrm{U}(\mathrm{w}-\beta)
$$

where $U^{\prime}>0$. Sometimes we refer to a policy $A \equiv\{\alpha, \beta\}$, and to the expected utility generated by that policy as $V_{t}\{A\}^{6}$. We do not require the preference to be convex for our results on the existence of equilibrium, nor that the so-called single-crossing property of preferences be satisfied. ${ }^{7}$ The key property of $\mathrm{V}_{t}(\alpha, \beta)$, which we assume is satisfied throughout the paper, is that the income consumption curve at the insurance price $\frac{P_{t}}{1-P_{t}}$ is the full insurance line, ${ }^{8}$ implying that at full insurance, the slope of the indifference curve equals the relative probabilities,

$$
-\frac{\frac{\partial \mathrm{V}_{\mathrm{t}}(\alpha, \beta)}{\partial \alpha}}{\frac{\partial \mathrm{V}_{t}(\alpha, \beta)}{\partial \beta}}=\frac{P_{t}}{1-P_{t}} \equiv q_{t}
$$

so that will full information, equilibrium would entail full insurance for each type at their own odds.

The profit $\pi_{t}$ of a contract $(\alpha, \beta)$ that is chosen by t-type $(\mathrm{t}=\mathrm{H}, \mathrm{L})$ is $\pi_{t}(\alpha, \beta)=\left(1-P_{t}\right) \beta-P_{t} \alpha$. $\pi_{t}(\alpha, \beta)=0$ is defined as the t-type's zero profit locus (the break-even locus). We sometimes write the profits associated with policy $A$ purchased by type $\mathrm{t}$ as $\pi_{t}\{A\}$. Figure 1 illustrates the zero-profit locus for a firm selling insurance to a t-type (OB and $O C$, respectively) or both types of individuals (OD) by a line from the origin with the slope being $q_{t}\left(\equiv \frac{P_{t}}{1-P_{t}}\right)$ or $\bar{q}\left(\equiv \frac{\bar{P}}{1-\bar{P}}\right)$, respectively. The latter is referred to as the "zero profit pooling line."

[FIGURE 1 ABOUT HERE]

There are $\mathrm{N}$ firms and the identity of a firm is represented by $j$, with $j \in M(\equiv\{1,2,--, N\})$. An

\footnotetext{
${ }^{5}$ This has become the standard formulation since RS. In practice, customers pay $\beta$ the period before the (potential) accident, receiving back $\alpha+\beta$ in the event the accident occurs, i.e. a net receipt of $\alpha$.

${ }^{6}$ Similarly, if the individual purchases policies $A$ and $B$, we can refer to the expected utility generated as $V_{t}\{A+B\}$.

${ }^{7}$ Indeed, we do not even require preferences to satisfy the conditions required for behavior towards risk to be described by expected utility. We also do not even require quasi-concavity. We also allow for more general preferences, e.g. with a different utility function $U_{t}($.$) for each type t$.

${ }^{8}$ That is, even if the indifference curve is not quasi concave, after being tangent to a given isocline with slope $\frac{P_{t}}{1-P_{t}}$, at full insurance, it never touches the isocline again.
} 
individual may purchase multiple policies. A set of the benefits and premiums of the insurance policies purchased in the aggregate by each type of individual, denoted by $E=\left\{\left(\alpha_{t}, \beta_{t}\right)\right\}_{t=H, L}$, is called an allocation.

\section{Rothschild-Stiglitz with Secret Contracts}

Central to the analysis of RS was the assumption that there was sufficient information to enforce exclusivity; an individual could not buy insurance from more than one firm. As RS realized, once we introduce into the analysis unobservable contracts in addition to the observable ones, the whole RS framework collapses, because exclusivity cannot be enforced. We now discuss briefly the consequences of introducing secret contracts; the interested reader is referred to the companion paper "Characterization, Existence, and Pareto Optimality in Insurance Markets with Asymmetric Information with Endogenous and Asymmetric Disclosures: Revisiting Rothschild-Stiglitz" (Stiglitz et al 2018) for details.

As we have noted, central to the RS analysis was, with exclusivity, the existence of contracts that break a putative pooling equilibrium; without exclusivity some of these contracts no longer do so, because they will be taken up by not only low risk individuals, but also high risk individuals who will supplement the given contract with undisclosed insurance at price $q_{H}$. Such insurance breaks even and so will always be on offer. Yet it turns out that there always exists some contract that even with secret insurance breaks a pooling equilibrium. ${ }^{9}$ But without exclusivity, the separating contracts from RS are also not equilibrium contracts, as illustrated in Figure $1 .{ }^{10}$ It follows that with a fixed information structure (where firms that disclose their sales always do so and those that don't never do so) there never exists a RS competitive equilibrium. ${ }^{11}$ In what follows we investigate the consequences of introducing endogenous and potentially asymmetric information disclosure about contract purchases into the RS model.

\footnotetext{
${ }^{9}$ Any contract $X$ such that $V_{L}\{X\}>V_{L}\left\{E_{p}\right\}, V_{H}\{X+Y\}<V_{H}\left\{E_{p}\right\}$, where $E_{p}$ is a putative pooling equilibrium and $Y$ is the utility-maximizing policy supplemental to contract $X$ at price $q_{H}, \pi_{L}\{X\}>0$ breaks the pooling equilibrium. It is easy to show that the set of policies satisfying the above inequalities (which we call "area $z$ ") is not empty, as illustrated by the shaded area in Figure 4.

${ }^{10}$ In Figure 1, the equilibrium separating set of contracts are given by $\{B, C\}$, where $C$ is the full insurance contract that maximizes the high-risk individual's inequality at price $q_{H}$, and $\mathrm{B}$ is the contract that maximizes the low risk individual's utility, subject to the self-selection constraint (so the high risk individual will not buy it) and the zero profit constraint (i.e. its price must be greater than or equal to $q_{L}$ ). Under RS, any separating policy for the low risk individual, which is illustrated by $\mathrm{OB}$ in Figure 1 , will be purchased by the high risk individual when he can supplement that policy with secret insurance at price $q_{H}\left(B C^{\prime}\right)$, and thus fails to separate.

${ }^{11}$ Recall the definition of a RS competitive equilibrium: a set of insurance policies (offers) such that no new policy can be offered which will be taken up and make a profit.
} 


\section{Pareto efficiency with undisclosed policies}

In this section, we consider the set of efficient insurance allocations under the premise that there exists a secret (undisclosed) policy being offered at the price $q_{H}$. We can think of this as a "constrained Pareto Efficient" allocation-where the constraint is that the government cannot proscribe the secret provision of insurance, unlike the Pareto Efficient allocations associated with the RS model, where government could restrain such provision. ${ }^{12}$ We use the following ex-interim variant of constrained Pareto efficiency ${ }^{13}$ :

Definition (Constrained Pareto Efficiency). An allocation $\mathrm{E}=\left\{\left(\alpha_{t}, \beta_{t}\right)\right\}_{t=H, L}$ is constrained Pareto-efficient (CPE for short) if the government cannot force disclosure and there does not exist another feasible allocation (i.e. one which at least breaks even), and leaves each type of consumer as well off and at least one type strictly better off.

In the presence of a contract that secretly offers any amount of insurance at a price $q_{H}$, therefore, a high-risk individual with a less-than-full insurance policy $(\alpha, \alpha q)$ would always supplement it by purchasing additional insurance at $q_{H}$ to reach a full-insurance policy $\{\gamma(\alpha, \alpha q), \delta(\alpha, \alpha q)\}$, where

$$
\begin{aligned}
& \gamma((\alpha, \alpha \mathrm{q}))=\frac{1}{1+q_{H}}\left[d+\left(q_{H}-q\right) \alpha\right] \\
& \delta\left((\alpha, \alpha \mathrm{q})=d-\gamma(\alpha, \alpha \mathrm{q})=\frac{1}{1+q_{H}}\left[q_{H} d-\left(q_{H}-q\right) \alpha\right]\right.
\end{aligned}
$$

The derivations of (2) and (3) can be found in Appendix B. Denoting by $\mathrm{H}(\alpha, q)$ the expected utility that a high-risk individual with a less-than-full insurance policy $(\alpha, \alpha q)$ (where $\alpha(1+q)<d)$ can obtain by supplementing it with the desired amount of insurance at a price $q_{H}$, we can show the following Lemma with the proof being relegated to Appendix B:

Lemma 1: $\mathrm{H}(\alpha, q)$ is decreasing in $q$ while it is increasing (respectively, decreasing) in $\alpha$ if $q<$ (respectively, $>$ ) $q_{H}$.

\footnotetext{
12 The analysis of PE allocations in the RS model is in Stiglitz (2009). The terminology may be confusing. It focuses on the constraints imposed by the government-that it cannot restrict the secret sale of insurance. From the perspective of the market, of course, it is an "unconstrained" equilibrium - they do not face the constraint of disclosing.

${ }^{13}$ See Holmstrom and Myerson (1981) and Greenwald and Stiglitz (1986)
} 
Lemma 1 implies that a high-risk individual would always like to purchase more insurance (up to full insurance) at a price lower than $q_{H}$ in the presence of the undisclosed supplemental purchase of insurance at $q_{H}$. Lemma 1, which plays a critical role for the results in this paper, holds without the assumption of quasi-concavity of the utility function.

\section{[FIGURE 2 ABOUT HERE]}

In characterizing CPE allocations, we will first consider a set of allocations that satisfies the zero-profit constraint ${ }^{14}$, and then narrow it down to the set of feasible allocations satisfying the self-selection constraints in the presence of the undisclosed contracts. Lemma 2 provides a characterization of all zero profit allocations.

Lemma 2: An allocation $\left\{\left(\alpha_{t}, \beta_{t}\right)\right\}_{t=H, L}$ yielding zero profit can without loss of generality be represented as a pooling allocation $(\hat{\alpha}, \hat{\beta})$ plus a set $\left(\alpha_{t}^{S}, \beta_{t}^{S}\right)$ of supplemental allocations for $t=H, L$ :

$$
\alpha_{\mathrm{t}}=\hat{\alpha}+\alpha_{t}^{S}, \beta_{\mathrm{t}}=\widehat{\beta}+\beta_{t}^{S} \text { where } \hat{\beta}=\bar{q} \hat{\alpha} \text { and } \beta_{t}^{S}=q_{t} \alpha_{t}^{S}
$$

The proof can be found in the Appendix C. Lemma 2 is illustrated in Figure 2, which shows how an allocation $(B, C)$ (that yields zero profit) can be decomposed into a pooling allocation $A$ and the two supplemental allocations ( $\mathrm{AC}, \mathrm{AB})$. When $\left(\alpha_{t}, \beta_{t}\right)$ is a full-insurance allocation, $\hat{\alpha}=\frac{1}{1+\bar{q}} d$ and $\widehat{\beta}=\frac{\bar{q}}{1+\bar{q}} d$, $\alpha_{t}^{S}=0=\beta_{t}^{S}$. Lemma 2 implies that an allocation yielding zero profit can be characterized by the three parameters $\hat{\alpha}, \alpha_{H}^{S}$ and $\alpha_{L}^{S}$.

Lemma 3 shows that the self-selection constraints in the presence of the undisclosed policies result in the following restrictions on feasible allocations:

Lemma 3: Any feasible allocation must satisfy:

i) $\quad \alpha_{H}^{S}=\frac{1}{1+q_{H}}[d-(1+\bar{q}) \hat{\alpha}]$ for $\hat{\alpha} \leq \frac{1}{(1+\bar{q})} d$.

ii) $\alpha_{L}^{S}=0$.

Lemma $3 \mathrm{i}$ ) results from (2) and the fact that $\alpha_{H}^{S}=\gamma((\hat{\alpha}, \hat{\alpha} \bar{q}))-\hat{\alpha}$, i.e., that a feasible allocation for highrisk individuals should entail full-insurance. To see Lemma 3 ii), note that if $\alpha_{L}^{S}>0$, the allocation would not satisfy the self-selection constraint. This is because then high-risk individuals, after choosing $(\hat{\alpha}, \hat{\alpha} \bar{q})$

\footnotetext{
${ }^{14}$ It is easy to show that this is a necessary condition for a CPE allocation.
} 
(A in Figure 2), would supplement it by choosing supplemental policy $\mathrm{AB},\left(\alpha_{L}^{S}, \alpha_{L}^{S} q_{\mathrm{L}}\right)$, and supplement that with secret insurance $\mathrm{BC}^{\prime}$, bringing him to full insurance which yields $\mathrm{H}\left(\hat{\alpha}+\alpha_{L}^{S}, q^{\prime}\right)\left(=V_{H}\left\{C^{\prime}\right\}\right.$ in Figure 2), where $q^{\prime}=\frac{1}{\hat{\alpha}+\alpha_{L}^{S}}\left(\bar{q} \hat{\alpha}+q_{L} \alpha_{L}^{S}\right)<\bar{q}$. By Lemma $1, \mathrm{H}\left(\hat{\alpha}+\alpha_{L}^{S}, q^{\prime}\right)>\mathrm{H}(\hat{\alpha}, \bar{q})$, because $q^{\prime}<\bar{q}$ and $\hat{\alpha}+$ $\alpha_{L}^{S}>\hat{\alpha}$. Lemma $\left.3 \mathrm{ii}\right)$, of course, implies that $\left(\alpha_{\mathrm{L}}, \beta_{\mathrm{L}}\right)=(\hat{\alpha}, \hat{\beta})$.

A feasible allocation for type $t$ that satisfies Lemma 3 is denoted by $Z_{t}(\hat{\alpha})(t=H, L)$, which is characterized by the parameter $\hat{\alpha}$ : by Lemma 3,

$$
\begin{aligned}
& Z_{H}(\hat{\alpha})=(\gamma((\hat{\alpha}, \hat{\alpha} \bar{q})), \delta((\hat{\alpha}, \hat{\alpha} \bar{q}))) \\
& Z_{L}(\hat{\alpha})=(\hat{\alpha}, \bar{q} \hat{\alpha})
\end{aligned}
$$

where $\hat{\alpha} \in\left[0, \frac{1}{1+\bar{q}} d\right]$. The feasible allocation $\left\{Z_{t}(\hat{\alpha})\right\}_{t}$ with $\hat{\alpha}=\frac{1}{1+\bar{q}} d$ is the full-insurance pooling allocation, whereas that with $\hat{\alpha}=0$ implies that the low risk individual gets no insurance. ${ }^{15}$

Only a subset of the set of feasible allocations are CPE. Define $\bar{\alpha}$ as

$$
\bar{\alpha}=\operatorname{Argmax}_{\hat{\alpha}} V_{L}(\hat{\alpha}, \bar{q} \hat{\alpha})
$$

$\bar{\alpha}$ is the amount of insurance that is the most preferred by low-risk individuals given a price $\bar{q}$, as illustrated by $A^{*}$ in Figure 3.

\section{[FIGURE 3 ABOUT HERE]}

(4) implies that $V_{H}\left\{Z_{H}(\hat{\alpha})\right\}$ or $\mathrm{H}(\hat{\alpha}, \bar{q})$ is increasing in $\hat{\alpha}$ because $\bar{q}<q_{H}$ (by Lemma 1 ). Thus conditions (4)-(6) imply that a feasible allocation $\left\{Z_{t}(\hat{\alpha})\right\}_{t}$ is not CPE if $\hat{\alpha}<\bar{\alpha}$, because both types of individuals could be made better off as $\hat{\alpha}$ increases to $\bar{\alpha}$. Also, a feasible allocation $\left\{Z_{t}(\hat{\alpha})\right\}_{t}$ with $\hat{\alpha}>\bar{\alpha}$ does not dominate the allocation $\left\{Z_{t}(\bar{\alpha})\right\}_{t}$, implying that $\left\{Z_{t}(\bar{\alpha})\right\}_{t}$ is CPE. Under the assumption of convex preferences, by (4) and (6), a feasible allocation $\left\{Z_{t}(\hat{\alpha})\right\}_{t}$ is also CPE if $\hat{\alpha}>\bar{\alpha}$ because $V_{H}\left\{Z_{H}(\hat{\alpha}\}>\right.$ $V_{H}\left\{Z_{H}(\bar{\alpha}\}\right.$ while $V_{L}\left\{Z_{L}(\hat{\alpha})\right\}$ is decreasing in $\hat{\alpha}$ for $\hat{\alpha}>\bar{\alpha}$ (See Figure 3). ${ }^{16}$ We have thus established the following Proposition:

\footnotetext{
${ }^{15}$ It can be shown that this is also the allocation associated with the Akerlof price equilibrium (the natural extension to the insurance market of Akerlof's [1970] lemons model, when it exists.

${ }^{16}$ Note that the convexity assumption affects the constrained pareto efficiency of the non-equilibrium allocations $\left\{Z_{t}(\hat{\alpha})\right\}_{t}$ with $\hat{\alpha}>\bar{\alpha}$. The fact that $\left\{Z_{t}(\bar{\alpha})\right\}_{t}$ is CPE is not affected by the convexity assumption.
} 
Proposition 2. The allocation $\left\{Z_{t}(\bar{\alpha})\right\}_{t}$ is CPE, which entails a pooling allocation $(\bar{\alpha}, \bar{q} \bar{\alpha})$ for the low-risk individuals and the pooling allocation $(\bar{\alpha}, \bar{q} \bar{\alpha})$ supplemented by additional insurance at price $q_{H}$ up to the full-insurance for the high-risk individuals. Under the assumption of convex preferences, the set of CPE allocations are $\left\{Z_{t}(\hat{\alpha})\right\}_{t^{\prime}}$ where $\hat{\alpha} \geq \bar{\alpha}$.

\section{Game Form, Contracts, and Equilibrium}

Individuals are allowed to purchase multiple policies from a single or multiple firms. (A characteristic of the equilibrium will be that an individual will purchase only a single policy from any firm.) An individual or his insurer may disclose to other firms all or some information about the set of policies purchased or sold, respectively. Information revealed must be truthful, but individuals or firms may choose not to reveal some or all information. ${ }^{17}$ What is critical about the information disclosure in the model is that they cannot reveal the fact that they have not purchased a particular policy. ${ }^{18}$

In RS, insurance contracts are defined by a benefit, a premium, and an exclusivity provision. Implicitly, there is a cancellation rule: if the individual purchases insurance from others, the policy is cancelled. Here, we extend this by a more complicated restriction on insurance purchases (e.g. that they not exceed a total aggregate amount) and we introduce a disclosure provision, specifying what information the firm discloses to whom. Below more precise specifications of a contract and the game form are provided.

\subsection{Game Form}

We employ a two-stage game consistent with a conventional framework of a screening model.

- First stage: each firm offers a contract specifying a set of policy offers and a rule of information disclosure. The policy offers come with restrictions on what insurance individuals can buy from other insurers, but the implementation of those restrictions depends on the information available to the insurer. Thus, both are made conditional upon information disclosed by a consumer and any other information that might be available to the firm. ${ }^{19}$

\footnotetext{
${ }^{17}$ To ensure truthful revelation, we may suppose that whenever disclosing information an insurer or an individual may show to other firms the policies traded between them.

${ }^{18}$ If they could, we would be back in the world of exclusivity.

${ }^{19}$ We have also explored sequential versions of this game, where the individual purchases from different firms
} 
- Second stage: consumers purchase policies and disclose information about them (possibly selectively) to their potential insurers, following which each firm executes its contract for its consumer as announced in the first stage by disclosing information as specified by its disclosure rule. Consumers whose insurance purchases are found to be inconsistent with the policy restrictions have their policies cancelled..$^{20} 21$

In fact, because cancellations only occur when consumers have violated the restrictions imposed by a policy, in equilibrium, cancellations never occur. The model is similar to the one by Jaynes (1978) as interpreted by Hellwig (1988), subsequently referred to as the JH model. ${ }^{22}$ But it is critically different from the $\mathrm{JH}$ model in that ours introduces information disclosure by consumers.

The introduction of the consumer disclosure is absolutely essential to our analysis; consumers' asymmetric disclosure of information about insurance sales leads, as we have noted, to the existence of a competitive equilibrium. ${ }^{23}$ If the firm only had its own information available to decide to whom to disclose to, it would have to make symmetric disclosures, because it would have no basis for differentiation. A critical aspect of the game form described above is that a contract offered by a firm does not depend upon those offered by other firms. ${ }^{24}$ We thus rule out any strategic element in the behavior of firms. In section 6 , we show that there exists a non-strategic, non-reactive, competitive equilibrium.

\subsection{Contract Specifications}

sequentially, and makes a decision sequentially about which information about previous purchases to reveal. Then policy offers will be conditional on the information revealed at the time of purchase as well as information that may eventually be revealed to the firm. The results of that analysis are identical to those presented here.

${ }^{20}$ Note that within the second stage there are actually four sequential steps: consumer purchases; consumer disclosures; firm disclosures based on consumer disclosures; firm cancellations based on consumer and firm disclosures. In a more complicated version of our model, there can be further steps: after the initial consumer and firm disclosures, there can be further firm disclosures (since disclosure is a function of information, and the information set of firm $j$ has changed with the disclosures). These additional disclosures can lead to still further disclosures.

${ }^{21}$ The cancellations can be shown, in the more detailed model formulated below, to be time consistent.

${ }^{22}$ There is an inessential difference concerning our formulation of the cancellation strategy, which in Hellwig is made to be an explicit part of the firm strategy, while we have assumed that when the restrictions imposed are not satisfied, the policy is cancelled. As we note below, our analysis can be extended in a straightforward way to the case where there is an explicit cancellation strategy, without changing any of the results.

${ }^{23}$ Hellwig (1988) showed that there does not exist an equilibrium in the above model with no consumer disclosure.

${ }^{24} \mathrm{~A}$ firm may respond to the information about a particular consumer that may be revealed by the consumer or by his other insurers, but, as Hellwig $(1988$, p. 157) also points out, the response by a firm to customer information is quite different in nature from its response to contracts offered by other firms. Below, we will consider an equilibrium contract which is conditional only upon the amount of insurance a consumer purchases elsewhere. We allow a deviant firm to offer any contract that is conditional upon any information received. In contrast to Jaynes (1978), ours is not a reactive equilibrium. 
An insurance contract consists of two components (i) a policy, defined by a price, $q$, a benefit, $\alpha$, and a set of restrictions that have to be satisfied (to the knowledge of the insure ${ }^{25}$ ) if the policy is to go into effect; and (ii) an information disclosure rule. The set of contracts (policies with their restrictions, and disclosure rules) that are conceivable is quite rich; all that is required is that firms can only disclose a subset of what they know, and can impose restrictions that can only be implemented based on the knowledge of the insurer. But we are able to show that there exists an equilibrium with a simple set of contracts and disclosure rules (one which naturally implements the allocation described in section 3 ). In this equilibrium, the fixed number of firms $\mathrm{N}$ is divided into two groups. What we call the established firms offer insurance at price $\bar{q}$ (the pooling price), with a restriction that no one (to their knowledge) purchases in aggregate more than $\bar{\alpha}$, the amount that maximizes the utility of low risk individuals at that price. ${ }^{26}$ The firms' contracts are such as to induce everyone to comply and to reveal that information.

The remaining firms (the secret firms) sell undisclosed insurance at price $q_{H}$, which is purchased only by high risk individuals, and brings these individuals to full insurance.

To simplify the notation and exposition, we begin by assuming all firms (other than a deviant firm) have to offer insurance with a single price, with possibly imposing a constraint on aggregate purchases, and then show that, given the equilibrium contracts described, no firm would want to offer any other contract(s) (e.g. with any other set of restrictions or disclosure rules). ${ }^{27}$ Similarly, while we allow disclosure of any information within the information set of firms, the equilibrium entails only disclosure of information revealed to it by its consumers plus what it knows from its own sales. Had we not restricted the firm to only use that information, it would not have made any difference. ${ }^{28}$

\footnotetext{
${ }^{25}$ It would make no sense to impose a restriction that was not enforceable, i.e. for which the insurer did not have the requisite information. Thus, in the equilibrium described below, the disclosure rules ensure that the contract restrictions, as imposed, are enforceable. A firm might like to impose further restrictions (e.g. exclusivity, or that those that purchase insurance from it not purchase supplemental insurance at a price greater than $\bar{q}$, but such restrictions are not enforceable.

${ }^{26}$ In the more general case (explored in Stiglitz et al 2018) the insurance firm can offer any set of policies defined by a benefit and premium $\{\alpha, \beta\}$. As we note below, in the analysis of the equilibrium, we impose no restrictions on what deviant firms can do.

${ }^{27}$ That is, the constraint on the set of contracts just imposed is, in fact, not a binding constraint.

${ }^{28}$ The analysis would have to be complicated in one way: there would have to be a series of sub-periods in the second stage. In each sub-period, the firm takes the information it has received from other firms, and on the basis of that information, may make further disclosures. At each substage the information to be revealed is a function of the information that the firm has at that stage. Then it is possible that as the firm gathers more information, it may decide to disclose a subset of the information to some firms that it had not previously disclosed to. (Obviously, it cannot "undisclose" information that it has previously disclosed.) Since there is a limit to the information that can be revealed (i.e. full information about the individual's purchases) the process must converge. None of this is relevant
} 


\section{(i) Insurance Policies}

$(\alpha, \beta)$ is given by $(\alpha, \alpha q)\left(\in R_{+}^{2}\right)$, where $q\left(\equiv \frac{\beta}{\alpha}\right)$ indicates the price of insurance offered. With the index $i$ being suppressed for simplicity, a policy purchased by individual $i$ from firm $j$ is represented by $x(j)\left(\in R_{+}^{2}\right)$ :

$$
x(j) \equiv\left(\left(\alpha_{j}, \alpha_{j} q_{j}\right)\right){ }^{29}
$$

while the set of policies purchased from all of the established insurers is denoted by $\hat{X}\left(\equiv\{x(j)\}_{j \in K}\right)$, where $\mathrm{K}(\subset \mathrm{M})$ is the set of the established insurers for an individual $i$, i.e., $x(j)>0, \forall j \in K$.

The amount $\alpha_{j}$ of insurance offered by a firm $j$ may be required to satisfy a restriction, which turns out in equilibrium to take a simple form described below. The restriction can be in general represented by a set of insurance amounts allowed, denoted by $\psi_{j}\left(X_{j}^{T}\right)$, where $X_{j}^{T}(\subseteq \hat{X})$, as defined by (10) below, is the total information (about the individual's purchases) available to the firm $j$. That is,

$$
\alpha_{j} \in \psi_{j}\left(X_{j}^{T}\right)
$$

A policy offer by a firm $j$ may in general be represented by $\left(q_{j}, \psi_{j}\left(X_{j}^{T}\right)\right)$. The policy offer made by a firm $j$ in the equilibrium we analyze in section 6 , denoted by $\left(q_{j}^{*}, \psi_{j}^{*}\left(X_{j}^{T}\right)\right)$, takes the following forms:

(a) Established firms $j(=1,--, n$, for $n<N)$ : $q_{j}^{*}=\bar{q}$, while $\psi_{j}^{*}\left(X_{j}^{T}\right)$ is described by (8) below.

In RS, the low price insurance policy was offered with a simple restriction: no one could purchase insurance from any other firm (the exclusivity provision). Here, we allow the individual to purchase from other insurance firms, but the equilibrium contract imposes restrictions on the amounts of insurance which an individual can purchase from other firms. The intent of these restrictions is the same as the exclusivity provision: if possible, to exclude high risk individuals from buying insurance, but at least to limit the amount of insurance purchased by high risk individuals, who will be those who want to buy high levels of insurance. (In equilibrium, the established firm succeeds in the latter, but not the former.)

In the particular equilibrium that we analyze in section 6 , the firm's policy simply limits the total amount of insurance that the individual can buy that it knows about. More precisely, in the equilibrium

\footnotetext{
along the equilibrium path, because (as we will see) all purchases are truthfully revealed.

${ }^{29}$ We assume for simplicity of exposition in this specification that an individual purchases one policy from a firm. We will show below (Lemma 4) that even if we allow firms to sell an individual more than one policy, no firm would do so in equilibrium. We allow a deviant firm to sell multiple polies to an individual.

${ }^{30}$ Note that a contract with a restriction of this form is consistent with a competitive equilibrium, as pointed out by Hellwig (1988). Furthermore, a restriction based on information disclosed by other firms is inevitable in controlling the excessive purchases by high-risk individuals of insurance at the pooling price in a non-exclusive environment. In this paper we show that this type of a restriction, together with a particular type of disclosure rule by firms based on consumer disclosure also turns out to be critical in sustaining an equilibrium under adverse selection.
} 
contracts analyzed in section 6 , the firm offers a consumer $i$ any amount of insurance so long as aggregate purchases of insurance (that it knows about) including its own sales is equal to or less than $\bar{\alpha} \cdot{ }^{31}$ Because it knows that high risk individuals will never disclose their purchases from the secret firms (and the secret firms won't disclose their sales), it can focus its restrictions on (what it knows about) purchases from the established firms. The firm $j$ imposes the restriction $\psi_{j}^{*}\left(X_{j}^{T}\right)$ such that

$$
\psi_{j}^{*}\left(X_{j}^{T}\right)=\left\{\alpha_{j} \mid T\left(X_{j}^{T}\right) \leq \bar{\alpha}\right\} \quad \text { for } j=1,--, n .
$$

where $T\left(X_{j}^{T}\right)=\sum_{x(k) \in X_{j}^{T}} \alpha_{k}$, the sum of insurance amounts purchased from all the established firms (including the firm $j$ ) that the firm knows about.

If the restriction is violated, then the policy is cancelled. We can think of the cancellation in two different ways: (a) The policy is not enforceable. The insurance company is, of course, perfectly willing to accept the premium. The question is, what happens when the accident occurs. If a restriction in the policy is not satisfied, then the contract will be viewed as not valid, and the policyholder cannot collect. The policyholder, knowing that, will, of course, never violate a restriction that it knows the insurance firm can establish that it has violated. Thus, we can assume that the disclosures are made to the firm in a form that it could verify before a Court. (b) When the restrictions are violated, the firm has the right to cancel the policy. In the equilibrium analyzed below, we show that whenever it sees the restriction violated, its profits can be decreased but cannot be increased by issuing the policy, so that it has an incentive to cancel the policy. Of course, in either interpretation, cancellation will only occur if the firm knows that the restriction is violated. To determine that, we have to analyze disclosures.

(b) Secret firms $j(=n+1, \ldots, N): q_{j}^{*}=q_{H}$ with no restrictions i.e., offering (unlimited) insurance at $q_{H}$ :

$$
\psi_{j}^{*}\left(X_{j}^{T}\right)=R_{+}
$$

\section{(ii) Disclosure Rules}

In general an information disclosure rule by a firm $j$, denoted by $D I S_{j}$, specifies a set $R E_{j}(\subset M)$ of firms receiving information from $j$ about a particular individual ${ }^{32}$ and information $I N F_{j k}\left(\subseteq X_{j}^{T}\right)$ to be

\footnotetext{
${ }^{31}$ In a more general case, we can allow a broader range of restrictions.

${ }^{32}$ For the remainder of this section, without loss of generality, we focus on information about a particular individual.
} 
disclosed to a firm $k\left(\in R E_{j}\right)$, where, as before, $X_{j}^{T}$ (defined by (10) below) denotes all of the information available to firm $j$ about an individual's purchases. The information disclosed is obviously a subset of $X_{j}^{T}$.

The information disclosed by an individual $i$ to his insurer $j$ about purchases from others is denoted by $X_{j}^{o-j}(\subseteq \widehat{X})$, indicating that an individual cannot disclose a policy that he does not purchase although he may withhold from his insurer information about some policies purchased. Thus, the information set of firm $j$ about individual $i, X_{j}^{o}$, before receiving information from other firms is ${ }^{33}$

$$
X_{j}^{o} \equiv x(j) \cup X_{j}^{o-j}
$$

We suppose that whenever a policy $x(j)$ sold is disclosed, the identity $j$ of the insurer is also disclosed. Thus, the set $I(\subset M)$ of firms (including the firm $j$ ) disclosed as providing insurance by the consumer is given by:

$$
I \equiv\left\{k \in M \mid x(k) \in X_{j}^{o}\right\}
$$

Finally, all the information $X_{j}^{T}$ disclosed to firm $j$ by the consumer and by other firms would be

$$
X_{j}^{T} \equiv X_{j}^{o} \cup X_{j}^{-j}
$$

where $X_{j}^{-j}$ is the union of the information that is disclosed by all the other firms to $j$. In summary, a disclosure rule $D I S_{j}$ of a firm $j$ may be represented as follows:

$$
D I S_{j}\left(X_{j}^{T}\right)=\left(R E_{j}\left(X_{j}^{T}\right), I N F_{j k}\left(X_{j}^{T}\right)\right)
$$

specifying what firms will be disclosed to, and, given that there is some disclosure to firm $k$, what information is disclosed.

In section 6, we show that the equilibrium contract is such that the set of firms to which the firm discloses and what the firm discloses can depend on a subset of $X_{j}^{T}$, and the firm does not (need to) disclose all of the information at its disposal, only what has been disclosed to the firm by consumers and what the firm itself knows directly, i.e only $X_{j}^{o}$ is disclosed:

$$
D I S_{j}^{*}\left(X_{j}^{o}\right)=\left(R E_{j}^{*}\left(X_{j}^{o}\right), I N F_{j k}^{*}\left(X_{j}^{o}\right)\right)
$$

\footnotetext{
${ }^{33}$ By contrast, the only information available in the $\mathrm{JH}$ model is based on information about firm offers and information revealed by other firms.
} 
That is, the disclosure rule $D I S_{j}^{*}$ we consider in equilibrium specifies $R E_{j}^{*}$ and $I N F_{j k}^{*}$ as functions of $X_{j}^{o}$, a subset of all the available information $X_{j}^{T} \cdot{ }^{34}$ In particular, the established firms $(j=1,--, n)$

(a) disclose to all of the firms that have not been disclosed by the consumers as insurers, ${ }^{35}$ i.e. to

$$
R E_{j}^{*}\left(X_{j}^{o}\right)=\mathrm{M}-\mathrm{I}\left(X_{j}^{o}\right)
$$

(b) all the information that a firm $j$ has about a consumer that he has obtained from the consumer plus his own sales:

$$
I N F_{j k}^{*}\left(X_{j}^{o}\right) \equiv X_{j}^{o} \text {, for all } k \in R E_{j}
$$

while the secret firms $(j=n+1,--, N)$ make no disclosure:

$$
\begin{aligned}
& R E_{j}^{*}\left(X_{j}^{o}\right)=\emptyset \\
& I N F_{j k}^{*}\left(X_{j}^{o}\right)=\emptyset
\end{aligned}
$$

\section{Cancellation}

Now that we have developed the notation for disclosure, we can describe cancellations for the established firms. As we noted, when an individual makes a purchase which violates a condition of the insurance policy (as far as the seller knows), the policy is cancelled. ${ }^{36}$ For the specific equilibrium that we explore here, with the restriction $\psi_{j}^{*}\left(X_{j}^{T}\right)$ for the established firms (defined in (8)), a policy gets cancelled if

$$
\mathrm{T}\left(X_{j}^{T}\right)>\bar{\alpha}
$$

where $\mathrm{T}\left(X_{j}^{T}\right)$ is the sum of the purchases of the individual from all the established firms as known to the

\footnotetext{
${ }^{34}$ We show that firm can increase its profits by changing its disclosure rule, e.g. by expanding what it discloses. We impose no restrictions on the disclosure rules of a deviant firm.

${ }^{35}$ Note that, so long as consumers always make their optimal responses to the contracts offered by firms (to make sure that the policies they purchase are not cancelled), both in and out-of-equilibrium, the information set $X_{j}^{o}$ that is realized will be the same as the information set $X_{j}^{T}$ that is realized (that is what the firm actually knows is, in fact, embraced totally by what has been revealed to him by his customer, including what he has sold the customer.)

${ }^{36}$ Again, in a more general model, the insurer can decide as to whether to cancel, based on the information available to it and the inferences that it draws from that information. Hellwig (1988) emphasizes the importance of such a cancellation strategy in the model he investigates. In our model with endogenous information, a Nash equilibrium can be established with the simpler cancellation rule posited. In an alternative formulation, we can introduce a cancellation strategy, which specifies the conditions under which a policy will be cancelled (obviously, based on the information available to the firm at the time that the cancellation occurs, in the second period.) Individuals, of course, know the cancellation strategy at the time they buy the insurance. A restriction is only meaningful if it can and will be enforced. (See footnote 47 below for a fuller discussion of the incentive compatibility of our cancellation policy.)
} 
firm (i.e. based on his total information set $X_{j}^{T}$ ), though again it turns out that a simpler restriction, using only information disclosed by the consumer and the firm's own information, suffices. ${ }^{37}$

\section{Summary}

In our simplified model, a contract $C_{j}$ offered by a firm $j$ may in general be represented by a price, a possible constraint on quantities purchased, and a disclosure rule:

$$
C_{j}=\left\{q_{j} ; \psi_{j}\left(X_{j}^{T}\right) ; D I S_{j}\left(X_{j}^{T}\right)\right\}
$$

In section 6 we will establish that there always exists an equilibrium consisting of two groups of firms, the established firms $(j=1,---, n)$ and the secret firms $(j=n+1,--, M)$, one offering the secret contracts (no disclosure, unlimited insurance, at the price $q_{H}$ ), i.e. for which

$$
C_{j}^{*}=\left\{q_{j}^{*} ; \psi_{j}^{*}\left(X_{j}^{T}\right) ; D I S_{j}^{*}\left(X_{j}^{o}\right)\right\}
$$

where $q_{j}^{*}=\bar{q}$ (established firms) or $q_{H}$ (secret firms), $\psi_{j}^{*}\left(X_{j}^{T}\right)$ is defined by (8-1) (established firms) or by (8-2) (secret firms), and $D I S_{j}^{*}\left(X_{j}^{o}\right)$ is defined by $(12-1,2)$ (established firms) or by $(12-3,4)($ secret firms). For the readers' convenience, a summary of the notation introduced above is put in Appendix D.

\subsection{Consumer Response}

We now need to analyze in greater detail how consumers respond to the set of offers. An individual consumer $i$ responds optimally to any given set of contracts offered by firms in the first stage of the game. Formally, given a set $\left\{C_{j}\right\}_{j \in M}$ of contracts offered by firms, a consumer $i$ optimally chooses a set $K$ of his established insurers ${ }^{39}$, a set $\widehat{X}\left(=\{x(j)\}_{j \in K}\right)$ of policies to be purchased from them, $\left\{X_{j}^{o-j}\right\}_{j \in M}$ specifying which information about his purchases to disclose to whom, and amounts (if any) of insurance to purchase from other firms. Further, we assume that consumers tell the truth (disclose information) unless it is in their interests not to do so, which we refer to as the assumption of predilection for the truth.

\footnotetext{
37 That is, we can write the restriction as $\mathrm{T}\left(X_{j}^{o}\right) \leq \bar{\alpha}$. As noted, in this equilibrium, $X_{j}^{T}=X_{j}^{o}$.

${ }^{38}$ While the set of equilibrium policies is similar to the one analyzed by Jaynes (1978), the contracts differ markedly in their disclosure rules. In particular, in our model, the quantity offered (subject to cancellation) is conditional upon consumer-revealed information.

${ }^{39}$ In the equilibrium we analyze it will turn out that consumers are indifferent between purchasing from any particular established insurer; we suppose that they randomize uniformly over the established insurers to resolve indifferences. Other rules for resolving what to do when faced with indifference yield identical results.
} 
It is important to emphasize that we do not assume that consumers are always truthful - we only assume that if they are indifferent between truth telling any anything else, they tell the truth. In other words, this is a tie-breaking rule, not an assumption requiring truth-telling.

As for the optimization problem of the consumers, the problem takes the following form: they choose a set $\mathrm{K}$ (or K') of established (or secret) firms, a set of policies $x(k)\left(=\left(\alpha_{k}, \beta_{k}\right)\right)$ 's to purchase from them, and their disclosure rules $\left\{X_{j}^{o-j}\right\}_{j \in\left(K \cup K^{\prime}\right)}$ to maximize ${ }^{40}$

$$
\max _{\left\{\alpha_{k}, \beta_{k}\right\}_{k \in K \cup K^{\prime}}} V_{t}\left(\sum_{k} \alpha_{k}, \sum_{k} \beta_{k}\right)
$$

$$
\text { s.t. } \quad \alpha_{k} \in \psi_{k}\left(X_{k}^{T}\right), \quad \forall k \in K \cup K^{\prime}
$$

We say that a consumer's choice $\left\{\{x(j)\}_{j \in M^{\prime}}\left\{X_{j}^{o}\right\}_{j \in M}\right\}$ and disclosure rule is optimal if given $\{x(j)\}_{j \in M^{\prime}}$ $X_{j}^{o}$, and $\left\{D I S_{j}\left(X_{j}^{*}\right)\right\}_{j \in M}$ no policy is ever cancelled, and $\{x(j)\}_{j \in M}$ solves the above problem. ${ }^{41}$

\subsection{Definition of Equilibrium}

An equilibrium is defined in this model as follows:

An equilibrium is a set $\left\{C_{j}^{*}\right\}_{j}$ of contracts offered by firms such that, given $\left\{C_{j}^{*}\right\}_{j}$, there does not exist any other contract that a firm can offer to make positive profits once consumers optimally respond to firms' announced contracts. ${ }^{42}$

40 Of course, it is assumed that the insurance firm will implement the policy in the way that maximizes its profits, i.e. if the firm has the right to cancel a policy if the restriction is not satisfied, and it is optimal for it to do so, it is assumed that it will do so. If the firm has the right not to pay the benefit on a policy if the restriction is not satisfied, and if the insured event occurs, but the restriction is not satisfied (and it can establish that), then it will not pay the benefit.

${ }^{41}$ In the case where a policy cannot be enforced if a restriction is violated, the argument is trivial, for the individual would pay the premium, but never be able to collect. In the second interpretation given above, the argument that the individual could be no worse off not buying a cancelled policy that buying one is somewhat more subtle. For the set of purchases may affect to whom firm $j$ reveals information. The only reason to make a purchase that would be subsequently cancelled is to induce the firm not to reveal certain information to certain firms, in particular to the firm whose policy has been cancelled. But if the policy is subsequently cancelled, it means that nonetheless the relevant information was disclosed.

42 Of course, it is assumed that the insurance firm will implement the policy in the way that maximizes its profits, i.e. if the firm has the right to cancel a policy if the restriction is not satisfied, and it is optimal for it to do so, it is assumed that it will do so. If the firm has the right not to pay the benefit on a policy if the restriction is not satisfied, and if the insured event occurs, but the restriction is not satisfied (and it can establish that), then it will not pay the benefit. 
In this definition, we allow a deviant firm to offer any policy $x(j)$ with any restriction and to choose any disclosure rule based on any or all the information available to the firm.

\section{Equilibrium Allocations}

In this section, we show that the only possible equilibrium allocation is $\left\{Z_{t}(\bar{\alpha})\right\}_{t}$, the CPE allocation in the presence of undisclosed insurance which maximizes the well-being of the low risk individual, denoted by $\mathrm{E}^{*}{ }^{43}$

$$
E^{*} \equiv\left\{\left(\alpha_{t}^{*}, \beta_{t}^{*}\right\}_{t=H, L}=\left\{Z_{t}(\bar{\alpha})\right\}_{t=H, L}\right.
$$

This is true regardless of the strategies of various firms. We demonstrate that for any other posited equilibrium allocation, it is possible for an entrant to attract all of the (low risk) consumers and make a profit; hence that allocation could not be an equilibrium allocation.

The result is almost trivial: assume that there were some other equilibrium allocation, generated by any set of contracts purchased from any array of insurance firms, that was not $E^{*}$. Then there exists a contract $C^{\prime}$ that a deviant firm could offer, selling only one policy, entailing $\bar{\alpha}$ at a price $(\bar{q}+\varepsilon)$ (for a small $\varepsilon>0$ ), to each individual, which would profitably attract all low risk individuals, with high risk individuals supplementing that contract with secret insurance to bring the high risk individual to full insurance. The low risk individuals would purchase that contract regardless of its information disclosure and cancellation provisions, since they will not purchase supplemental insurance and will not be affected by these provisions. The putative equilibrium can thus be broken. We have thus established:

Theorem 1: There exists a unique allocation $E^{*}$ that an equilibrium, if it exists, has to implement.

\section{An Equilibrium with Endogenous Information Exists}

In this section we show that the contracts described in section 4 support the allocation $E^{*}$ as an equilibrium. (There may, of course, exist other equilibrium contracts. Our objective is simply to

\footnotetext{
${ }^{43}$ The allocation $E^{*}$ (and the generalization discussed in section 7) is sometimes called Glosten allocation (1994); still others refer to it as the Jaynes (1978) allocation. In the case of multiple types, both are generalizations of the equilibria characterized by Greenwald $(1979,1986)$ and Greenwald, Stiglitz, and Weiss (1984).
} 
demonstrate the existence of an equilibrium with endogenous information that is implemented using simple and interesting contracts.)

Several features of the equilibrium set of contracts $C_{j}^{*}$ (defined in (15)) are worth noting. First, in the posited equilibrium contracts, the restrictions pertain only to the revealed amount $\alpha$ of insurance, not upon the revealed price $q$ of insurance, and only on the amounts revealed by the consumer. ${ }^{44}$ Secondly, the contract entails asymmetric information disclosure based upon consumer-disclosed information. This is critical in sustaining an equilibrium. Without consumer disclosure in the model, as we have already noted, it would be impossible for any disclosure strategy to entail asymmetric information disclosure. ${ }^{45}$ And without asymmetric information disclosure based on consumer disclosure, it is impossible to sustain the equilibrium with the pooling contract. There has to be some information disclosure to prevent high risk individuals from "over-purchasing" the pooling contract. But with full information disclosure (of purchases of pooling contracts), exclusivity can be enforced, and hence the equilibrium involving a pooling contract can always be broken. We further emphasize below the importance of asymmetric information disclosure both in implementing $E^{*}$ and sustaining it against any deviancy.

\subsection{Proof of Existence of Equilibrium}

In showing that the equilibrium set of contracts $C_{j}^{*}$ implements $E^{*}$, we first prove the following lemma:

Lemma 4: In equilibrium, no established firm sells more than one contract to an individual.

For a proof, note it is only high-risk individuals who may want to have multiple contracts from their insurers. They would want to do so because they know if they report to an insurer that they have some insurance from some other firm, the insurer will not disclose information to that firm. Thus, they would like to underreport their purchases, to enable them to purchase more pooling insurance. The low risk individuals have no such incentives: their total purchases will be $\bar{\alpha}$, and they have nothing to hide. Knowing this, the only customers' sales that would be lost by selling only one policy would be high risk individuals. Accordingly, no firm would offer its customer more than one contract without charging a price at least equal to $q_{H}$. But high risk individuals would not accept it because they are at least as well off

\footnotetext{
${ }^{44}$ The fact that insurance sales are conditional on the purchases from other firms does not mean that this is a reactive equilibrium. As we noted earlier, in the reactive equilibrium, e.g. of Wilson, offers of insurance are withdrawn when any other firm makes a particular offer.

${ }^{45}$ See also Hellwig (1988).
} 
purchasing secret insurance at the price $q_{H}{ }^{46}$

We refer the attempt to deceive others through buying multiple policies from a company and disclosing only one such policy as contract manipulation. Lemma 4 says that in equilibrium, contract manipulation is not feasible. Given Lemma 4, we can show

Lemma 5: With the equilibrium set of contracts $C_{j}^{*}$, no individual purchases more than $\bar{\alpha}$ from the established firms.

This in turn implies that all purchase just $\bar{\alpha}$. While a formal proof is given in Appendix $C$, the intuition is clear. Assume an individual purchased more than $\bar{\alpha}$ in the aggregate from the established firms. Given $C_{j}^{*}$ he cannot disclose that he has purchased more than $\bar{\alpha}$ (to any of his insurers) because were he to do so, the policy would be cancelled. ${ }^{47}$ So there must not be full disclosure. But given $C_{j}^{*}$, there always exists at least one established firm who knows all of his established insurers. If the consumer does not disclose one of his insurers, say purchases from firm $j$, then all the other insurers disclose to the firm $j$ what they know about the consumer's purchases, and then the firm knows that the individuals has purchased more than $\bar{\alpha}$, so $j$ cancels its policy. But the individual would have known that, and so would not have purchased a policy from $j$. The one subtlety is the following: consider a situation with three established firms, $A, B$, and $C$. The high risk individual buys $1 / 2 \bar{\alpha}$ from each, discloses its purchases from $C$ to $A$, from $B$ to $C$ and from $A$ to $B$. Then $A$ reveals its sales to the individual to $B$, but $B$ already knew about it, and so on for the others. This is where our assumption that the firm reveals all of the information about the insurers of its customer that has been revealed by its customers, not just its own identity and sales, becomes relevant. $A$ knows about $C$, and thus reveals to $B$ information about $C$. But then $B$ knows that $A$ and $C$ are insurers of the consumer and how much has been purchased from each, cancelling its policy as it knows that the contract restriction has been violated. In the appendix, we show that this logic is perfectly

${ }^{46}$ Of course, high risk individuals (or their insurance firms) do not reveal their purchases of the supplemental policies at the high risk price, because if they did so, then all those selling pooling contracts would condition their sales on such supplemental policies not being bought (for such purchases reveal that the individual is high risk).

${ }^{47}$ Because the central condition of the policy has been violated. (See the discussion above on the interpretation of these restrictions.) Note that there is no reason not to cancel: either the contract is purchased by both low and high risk individuals, in which case the firm makes zero profits; or it is purchased just by high risk individuals, in which case it loses money. As we explain later (section 7), the equilibrium allocation can be supported by other disclosure rules, including one that entails disclosure of $\beta$ as well as $\alpha$. Given the disclosed $q=\beta / \alpha$ in an individual's allocation, there is a maximum $\alpha$ which a low risk individual would purchase. If the constraint $\psi$ imposed on an individual's purchases is such that at the disclosed q, $\alpha$ must be less than or equal to that amount, then cancellation is strictly incentive compatible, because the firm could infer that any individual violating that constraint was a high risk individual. 
general. ${ }^{48}$

There is one important corollary of Lemma 5: all individuals reveal their purchases from established firms to all established firms, since they have no reason not to (using the assumption of predilection for truth). We now prove the main theorem of the paper:

Theorem 2: The set of contracts $C_{j}^{*}$ implements the equilibrium allocation $E^{*}$ so that an equilibrium exists under the maintained assumptions ${ }^{49}$.

Proof: It is obvious that by lemma 5 , the set of contracts $C_{j}^{*}$ generates the equilibrium allocation $E^{*}$. Because of lemma 5 and its corollary, every established firm has the information required to effectively implement the allocation. There is no over-insurance by high risk individuals. They just purchase $\bar{\alpha}$ from the established firms and supplement it with undisclosed insurance at price $q_{H}$, bringing them to full insurance.

We now show the set of contracts $C_{j}^{*}$ sustains $E^{*}$ against any deviant contract. Note first that a deviant firm, indexed by $d$, cannot make profits by attracting only high-risk individuals in the presence of firms offering secretly any amount of insurance at $q_{H}$. This is because then no individual would pay a price higher than $q_{H}$ since a deviant firm cannot induce the established firms (with $C_{j}^{*}$ ) to sell more than $\bar{\alpha}$ at $\bar{q}$ under any circumstance. ${ }^{50}$ If the deviant firm $d$ attracts both high and low risk individuals ${ }^{51}$, its policy

\footnotetext{
${ }^{48}$ We have investigated alternative specifications of our model, where a firm discloses just its own sale to its customer, not what the consumer reveals to it. One variant entails insurance being purchased sequentially, with sales at any point being conditional on previous purchases. In this setting, a consumer would reveal to his insurer $k$ all of his previous purchases. Consider a consumer who wishes to hide his purchases because revealing that information would lead to the cancellation of the policy just purchased. If the consumer does not reveal his purchase say from insurer $k^{\prime}$ to $k$, insurer $k$ will disclose its sale to the previous insurer(s) that were undisclosed to it, who will cancel its policy sold to the consumer. The only reason that the consumer would not reveal previous purchases was because it had purchased more than $\bar{\alpha}$. That is, in this model, a firm does not need to disclose what its customer reveals to it to prevent its customer from over-purchasing insurance at $\bar{q}$.

${ }^{49}$ Recall that the set of equilibrium contracts $C_{j}^{*}$ includes the pooling policy at price $\bar{q}$ with aggregate purchase restrictions of $\bar{\alpha}$ and disclosure rule defined by (12) for the established firms and unlimited insurance at price $q_{H}$ with no disclosure for the other firms.

${ }^{50}$ This argument holds even when a deviant firm sells to an individual multiple policies without disclosing some of them to any other firm, which we call 'contract manipulation' as it would allow an individual to under-report his purchase without being detected. A deviant firm could attract high-risk individuals, and only high risk individuals, by the 'contract manipulation', which will be profitable, however, only when the firm charges them a total price higher than or equal to $q_{H}$. But no high-risk individual would accept this contract in the presence of the availability of undisclosed insurance at $q_{H}$.

${ }^{51}$ We assume that if a firm offers an insurance policy that is attractive to both high and low risk individuals, it attracts them in the same proportion as they exist in the population. If a policy is strictly preferred by high and low risk individuals, then, of course, it will attract all individuals.
} 
would have to charge a price $q_{d}$ equal to or lower than $\bar{q}$, yielding zero profits at best. A deviant firm $d$ can thus make positive profits only by attracting low-risk types only, i.e., only by a so-called creamskimming contract $C_{d}$. We will now show that in the presence of undisclosed insurance at price $q_{H}$, the contract $C_{d}$ always attracts high-risk individuals. To attract low risk individuals, $\mathrm{q}_{\mathrm{d}}<\mathrm{q}_{\mathrm{H}}$. It is obvious from Lemma 1 that, if he could, the high risk individual would purchase the contract ('OD' in Figure 4) plus additional pooling insurance ('DB' in Figure 4) up to $\bar{\alpha}$ plus supplemental undisclosed insurance ('BF' in Figure 4) at $q_{H}$, rendering the deviant contract unprofitable. ${ }^{52}$ The deviant firm knows this, and hence must put a constraint on the amount of supplemental pooling insurance that the individual can purchase. The problem is that no such constraint can be enforced. The high risk individual obviously will not disclose directly that he has made the supplemental pooling purchases. If the high risk individual discloses his purchase of the deviant contract to the established firms and limits his total purchases (combining what he has purchased from the deviant firm and amounts purchased from other established firms) to $\bar{\alpha}$, no established firm will cancel insurance that it has sold, and, by its disclosure rule of $C_{j}^{*}$, no established firm will reveal to the deviant firm its sales to the individual. Thus, firm $d$ cannot enforce any restriction entailing total purchases from itself, plus from the established firms, being less than or equal to $\bar{\alpha}$. Accordingly, high risk individuals will purchase the deviant contract, and it loses money. ${ }^{53}$ (Because any supplemental pooling insurance purchased from (another) established firm would not change the information set of the deviant firm d, the deviant firm could not enforce any restriction on such purchases. Also, similarly, the deviant firm cannot make its disclosure rule effectively depend on such supplemental insurance, and so can't use the disclosure rule to deter purchases.) ${ }^{54}$

\section{[FIGURE 4 ABOUT HERE]}

\section{Extensions to Cases with Many Types}

The result on existence of equilibrium can be extended to the case with many types. (See also

\footnotetext{
${ }^{52}$ Note in figure 4 that if the deviant contract is outside the shaded area, but preferred by the low risk individual, the high risk individual will purchase the policy even without supplemental pooling insurance. The only possible creamskimming deviant contracts must thus lie in the shaded area, preferred by the low risk individual (i.e. such that $H(\alpha$, q) $\leq \mathrm{H}(\bar{\alpha}, \bar{q})$ ) (using the notation we introduced in section 3 ) and such that $\pi_{L}(\alpha, \alpha q) \geq 0$.

${ }^{53}$ Finally, one can easily see that there is no other disclosure rule that can outperform the equilibrium disclosure rule (i.e. that can attract low-risk individuals only) for a deviant firm, because the best that such a disclosure rule could do would be to keep individuals from purchasing more than $\bar{\alpha}$ in the aggregate, which is already done by the equilibrium disclosure rule.

${ }^{54}$ As we noted earlier, this result holds whatever the deviant firm's disclosure rule and whatever other restrictions it imposes on purchases, establishing that there is no deviation that is profitable.
} 
Stiglitz-Yun (2016).) An equilibrium strategy in a case with the three types, for example, can be described in a similar way to the case with two-types. As illustrated in Figure 5 there is a pooling contract with all three types, contract $A$, the most preferred by the lowest risk type; and a partial pooling contract $A B$, with additional insurance entailing partial pooling, bringing together the two riskiest types, where $B$ is the most preferred along the zero profit line for partial pooling; and finally, a contract BC, at the high risk individual's odd, leading to full insurance to the highest risk type. (A, B, and C represent the total individual allocations for the three types.) In equilibrium, the lowest risk type consumers purchase A only, the "middle" risk consumers purchase $A$ and the supplemental policy $A B$, and the high risk individuals purchase $A$ and both supplemental policies $\mathrm{AB}$ and $\mathrm{BC}$.

\section{[FIGURE 5 ABOUT HERE]}

There are three types of firms, those selling the full pooling contract, those selling the partial pooling contract, and those selling the price contract to the high risk individuals. They adopt analogous information disclosure rule as in the case of two types of individuals. ${ }^{55}$ Consumers truthfully fully reveal to the other insurers their information about their purchases of the fully pooling contract $A$ (since all purchase the same amount, such information in equilibrium reveals no information about who they are). ${ }^{56}$ Consumers reveal information about their purchases of the partial pooling policies B only to firms not selling them the fully pooling policy (for if they disclosed that, the firm would know that they were of one of the two riskier types). By the same reasoning as in the two-type case, there is no room for a creamskimming deviant contract offering $D$ that profitably attracts only low or medium types, as riskier types are also induced to choose $\mathrm{D}$ as they can purchase additional insurance along the lines DE and EF (as shown in Figure 5); and by the same reasoning the partially pooling contract B can be sustained. ${ }^{57}$

\section{Discussion}

\section{Single Crossing Property}

The existence of equilibrium (Theorem 2) does not require either the so-called single-crossing

\footnotetext{
55 That is, revealing information only to firms not revealed to be sellers to individuals.

${ }^{56}$ Accordingly, no individual is worse off revealing his purchases of the full pooling contract A than not fully revealing his purchases. In fact, in the three-type case, an individual buying insurance from other than a fully pooling seller has an incentive to disclose his purchase from a fully pooling seller, because otherwise that insurer discloses to his fully pooling insurer his sales, and then the seller of policy would cancel the contract it sold to him.

${ }^{57}$ By the same token, there is no incentive for contract manipulation.
} 
property of preferences or the quasi-concavity of the utility functions, as has been almost universally assumed in the literature. The only property that we need about preferences to ensure existence of equilibrium is that the income consumption curve at the fair-odd price $q_{t}$ is the full insurance line.

\section{Multiple Policies}

There is one subtlety that has to be addressed: what happens if the deviant firm offers a menu of policies, in particular one purchased by high risk individuals, the other by low risk individuals? Is it possible that such a pair of policies-with cross subsidization-could break the equilibrium? In Appendix D of the companion paper (Stiglitz et al. 2018) we show that, even when a deviant firm offers multiple contracts at different prices, there still exists an equilibrium.

\section{Uniqueness of Equilibrium}

This paper has established the general existence of an equilibrium with endogenous information disclosure, using remarkably simple rules of disclosure. Even with simple rules, while there is a unique equilibrium allocation $E^{*}$, this can be supported by alternative contracts (with alternative disclosure rules and sets of restraints on the issuance of policies). For instance, if we extend the strategy space of firms so that contract sales to an individual can be conditioned on the price as well as the amount of insurance purchased, we can formulate a slightly different contract supporting the same equilibrium allocation $E^{*}$, as is shown in the Appendix E of the companion paper (Stiglitz et al 2018). ${ }^{58}$ In some ways the analysis of the equilibrium is simpler, ${ }^{59}$ but it entails using latent policies, policies which are only sold in response to out of equilibrium purchases from other insurance firms but which are not purchased in equilibrium. By contrast, our equilibrium does not entail any latent contract.

More complex rules, where through a series of rounds of disclosure, firms, for instance, might disclose information disclosed to them by other firms could presumably give rise to still other equilibria.

\section{Non-Collusive Nature of Equilibrium}

In this paper a group of firms with an equilibrium disclosure rule keeps an individual from benefitting from any non-disclosure and prevents a deviant firm from "breaking" the equilibrium. But this

\footnotetext{
${ }^{58}$ This equilibrium, as well as that where deviant firms can offer multiple contracts, also do not require that the single crossing property be satisfied.

${ }^{59}$ This equilibrium may allow for a simpler disclosure rule than that of $C_{j}^{*}$ of a firm: to disclose to others just its own sales, not information revealed by its customers. The rule of to whom the firm discloses, however, is still asymmetric, depending on information revealed by consumers.
} 
does not mean that the equilibrium we analyze in this one-shot game is a collusive equilibrium. No individual firm has an incentive to deviate from the disclosure rule (say in a way that would make it more attractive, enabling it to charge a higher price) because it would then end up with a disproportionately high proportion of high-risk individuals, and lose money.

As in RS, the market is competitive: there can be an arbitrarily large number of firms, and we can even extend the model to allow for entry. An insider (established) firm has no incentive to deter an outsider from entering the market, while any outsider firm entering the market would join the group of existing established firms by disclosing their information to the others (according to the equilibrium rule), because otherwise it would invite all the high-risk individuals.

\section{Previous Literature}

In the more than four decades since RS appeared, its disquieting results have given rise to a large literature, which we can divide into two major strands. The first looked for alternative equilibrium concepts or game forms, under which equilibrium might always exist, or under which a pooling equilibrium might exist. Rothschild and Stiglitz (1997) reviewed the literature as it existed to that point, suggesting that proposed seeming resolution of their non-existence result contravened plausible specifications of what a competitive market equilibrium should look like in the presence of information asymmetries. For instance, in Wilson's reactive equilibrium (1977), the entry of even a very small firm induces all firms to "react," by withdrawing their pooling contracts, making the deviant contract unprofitable and enabling the pooling equilibrium to be sustained. ${ }^{60}$ Dasgupta and Maskin (1986) provided a game theoretic formulation, showing that there was a mixed strategy equilibrium. ${ }^{61}$

\footnotetext{
${ }^{60}$ More recently Netzer and Scheuer (2014) have revived a variant of the Wilson-Miyazaki reactive equilibrium. Firms may "opt out" of the market after observing the contract offers of other firms. They show that even if the costs of opting out are nonzero, there is a unique outcome - the Miyazaki-Wilson one-so long as the costs are not too large.

${ }^{61}$ Mixed strategy equilibria (see also Farinha Luz (forthcoming)), while interesting as an analytic solution, are unpersuasive as a description of what any market might look like. The notion that one might go to an insurance firm and choose among lotteries which would assign probability distributions to benefits or premia, seems largely fanciful. Why that is so may necessitate an enquiry into behavioral economics, or into the economics of trust: how does one know that, say, the contract has been drawn from the purported probability distribution of contracts? One typically only sees one's own outcome.
} 
A second strand more related to the analysis here has explored the consequences of different information structures, in particular, the possibility of non-disclosed contracts. ${ }^{62}$ Most notable are a series of papers by Attar-Mariotti-Salanie (2011, 2014, 2016). ${ }^{63}$ Their 2014 model, employing strictly convex preferences, provides necessary conditions for the existence of an equilibrium. Applied to the insurance market, the equilibrium turns out to be the allocation where no one but the highest-risk individuals purchase insurance. The difference between their results and ours, where we have focused on endogeneity of information disclosure, are marked.

In their (2016) model they showed that an equilibrium entailing the allocation $E^{*}$ which we identified as the PE allocation which maximizes the welfare of the lowest risk individuals may exist only under a very restrictive set of preferences. ${ }^{64}$ When equilibrium exists, it entails the use of latent policies. Again, the difference between our results, where an equilibrium always exists and does not entail latent contracts, and theirs, which argues that undisclosed contracts makes existence less likely than in RS, is marked, and is attributable to our assumption of information endogeneity.

The closest works to our paper within the adverse selection literature are Jaynes $(1978,2011)$ and Hellwig (1988), who analyze a model with a certain type of strategic communication among firms about customers' contract information. Jaynes (1978) analyzes the same equilibrium outcome $E^{*}$ that we do. However, as Hellwig clarified, in Jaynes' (1978) 2-stage framework, the strategy of firms, including the associated strategic communication, is not a Nash equilibrium but a reactive equilibrium, with firms responding to the presence of particular deviant contracts, and thus Jaynes' formulation was subject to the same objections to reactive equilibria raised earlier. Hellwig formulated a four-stage game, in which

\footnotetext{
62 See also the earlier papers of Jaynes (1978) and Ales-Maziero (2012). Ales-Maziero (2012) focused on the case of adverse selection in a non-exclusive environment, characterizing the conditions for an equilibrium to exist and showing that an equilibrium, if it exists, is a separating one where only the highest-risk type purchase full insurance at the actuarially fair price. It has long been known that in an environment with secret contracts, there can never exist a RS (separating) equilibrium, and there cannot exist a price equilibrium in which both groups purchase insurance (an application of Akerlof's analysis to the insurance market, as illustrated in Theorem 3 below); under certain restrictive conditions there may exist a price equilibrium in which only the high risk individual purchases insurance.

${ }^{63}$ In their 2011 paper first (which is more akin to Akerlof's model of lemons and has a different scope of applications), using latent policies, they showed that an equilibrium exists under mild conditions with a unique equilibrium allocation, but only under the linear preferences in wealth in the presence of an aggregate capacity constraint. While AMS (2011) may have interesting implications for a variety of adverse selection models, it is not particularly relevant for the insurance market, where risk aversion is central.

${ }^{64}$ They considered a set of preferences such that any cream-skimming deviant policy (given the Glosten allocation) can be met by a latent policy, attracting high-risk individuals as well. The argument they developed for their analysis is in some sense similar to that used by Arnott-Stiglitz $(1987,2013)$ in their analysis of competitive equilibrium with moral hazard under non-exclusivity, but it requires more restrictive set of conditions to be imposed upon preferences.
} 
$E^{*}$ emerges as the sequential equilibrium, but as he emphasizes, it has the unattractive property that firm behavior (in the final two stages) is conditioned on knowing the offers of all firms, including the deviant firm. Thus, in contrast to our model, a firm cannot offer a contract in secret. Moreover, as Hellwig observes, "it is not the endogenous treatment of interfirm communication that solves the existence problem of Rothschild, Stiglitz, and Wilson. Instead the existence problem is solved by the sequential specification of firm behaviour which allows each firm to react to the other firms' contract offers." 65

While our work differs from that of Jaynes and Hellwig in several ways, perhaps most important is that we consider information revelation by consumers as well as firms. This allows the creation of asymmetries of information about insurance purchases between "established" firms and deviant firms. Without that, the pooling contract would not be able to be sustained. As we have noted, there is a delicate balance: on the one hand, one has to prevent overinsurance by high risk individuals purchasing pooling contracts (which requires established firms to know certain information), and on the other hand, one has to prevent a deviant firm from having enough information to enforce an exclusive contract that would break the pooling equilibrium. The consumer and firm information strategies which we describe do this. In contrast, at least in a simple game form, models relying on just firm information strategies cannot do this, because they do not have the information basis on which to engage in this kind of disclosure discrimination. ${ }^{66}$

\section{The No-disclosure Limited Information Price Equilibria}

A final strand of literature to which this paper is related is that which assumes no disclosure of insurance purchases, implying that the only information which a firm has about the purchases of an individual are the sales the firm itself, assuming that there is not anonymity in sales. This literature,

\footnotetext{
65 Jaynes (2018) analyzes a model with consumer revelation, as in Stiglitz and Yun (2016) and Stiglitz, Yun, and Kosenko $(2017,2018)$, coming to conclusions similar to those reached here.

${ }^{66}$ That is, at least in the initial round of disclosures, firm disclosure can only be based on individual purchases. Assume some firms sold policies which did not disclose their sales. High risk individuals would purchase such insurance beyond $\bar{\alpha}$, and the restriction that they not do so would not be enforceable. Thus, the putative allocation could not be sustained, since the non-disclosure pooling contracts would make a loss. On the other hand, if firms sold only full disclosure policies, then a deviant firm offering an exclusive contract in the region $z$ would be able to enforce exclusivity, and this would break the pooling allocation. Hence, again, the putative equilibrium could not be sustained. There has to be some basis on which firms can differentiate among whom to disclose; our consumer revelation mechanism provides this.
} 
however, does not endogenize the decision not to disclose, but takes that as given. The analytics developed in our analysis here enables us to easily establish two general non-existence theorems.

Non-existence of a partial information-no disclosure price equilibrium.

In the no-disclosure price equilibrium, the insurance firms simply take the price as given. However, while a firm doesn't know the size of the policies taken up by an individual from other firms, it knows what it has sold.$^{67}$ An insurance firm can offer a large policy - it knows to whom it sells, and can refuse to sell a second policy to the same individual. ${ }^{68}$ We define a partial information-no disclosure price equilibrium as an equilibrium where the insurance firm has at least information about the amount of insurance it has sold to an individual. A partial information-no disclosure price equilibrium is a set of contracts such that (a) each quantity-contract at least breaks even; (b) there exists a price at which each individuals can buy as much insurance at the price offered as he wishes and at which insurance premiums at least cover payouts; and (c) there does not exist any policy which (given the information structure) can be offered which will be purchased and make a profit.

Theorem 3a. There is no partial information-no disclosure price equilibrium where both types of individuals buy insurance.

Put differently, there is no "price equilibrium" when firms can offer an undisclosed quantity contract and ration the sale, say to one policy to a customer ${ }^{69}$. What is remarkable about Theorem $3 a$ is how little information is required to break the price equilibrium: the firm uses only its own contract information to implement the quantity constraint. We give a formal argument in the companion paper; in brief, the argument goes by contradiction, showing that if there is such an equilibrium with a single price, and both types purchasing different (but positive) amounts, there is always a cheaper deviant contract

\footnotetext{
${ }^{67}$ This would not be the case if individuals purchased insurance about an event affecting a third party, and firms sold such insurance without knowledge of the purchaser.

${ }^{68}$ In the context of moral hazard, the implication of this simple observation were explored in Arnott-Stiglitz (1991, 1987).

${ }^{69}$ We can also show that there is a Nash partial information price equilibrium where only the high risk individuals buy insurance if and only if $\alpha_{L}(\bar{q})=0$, where $\alpha_{L}(q)$ is the value of $\alpha$ that maximizes the low risk individual's utility (1) when the price of insurance is $q$. This condition is stricter than that in which there exists a price equilibrium with a single type: $\alpha_{L}\left(q_{H}\right)=0$. Thus, even a "corner" price equilibrium may not be a partial information price equilibrium. In a somewhat different set-up, Jaynes (1978) presents a set of similar results. The condition posited here for the existence of a partial disclosure price equilibrium, $\alpha_{L}(\bar{q})=0$, is stricter than that specified by Jaynes (1978), which would be equivalent to $\alpha_{L}\left(q_{H}\right)=0$. Jaynes (1978) shows that a price equilibrium $q^{*}$ at which each agent purchases his Walrasian demand (which in our model is the partial information-no disclosure price equilibrium) cannot be sustained in the presence of a fixed-quantity contract when more than one type of agent purchases insurance at $q^{*}$.
} 
(with quantity restrictions) that is purchased only by the low-risk types, thus breaking the equilibrium.

Non-existence of a partial information-no disclosure rationing equilibrium

It is natural to ask, if there is not a price equilibrium, is there some equilibrium, with say just fixed quantity contracts? Consider a case where the two groups are quite similar. Each insurance firm sells

insurance in fixed units, say $(\bar{\alpha}, \bar{\beta})$, the policy which is most preferred by the low risk individual along the break-even pooling line. The high risk individual would not want to buy two units of that insurance. But he would supplement his purchase with the undisclosed insurance at his own price, in an amount that brings him to full insurance. The analysis of this paper has shown not just that there does not exist a partial-disclosure price equilibrium but also that this kind of pooling contract cannot be an equilibrium: there is always a deviant policy that could be offered that would be taken up only by the low risk individuals, given the posited information structure ${ }^{70}$. In other words,

Theorem $3 b$. Given a partial information structure, where firms only know the quantity of insurance they have sold to any individual, there is no equilibrium, ever, where both groups buy insurance.

By contrast, with the more complex endogenous information structure described in the paper, there is always an equilibrium.

\section{Concluding Remarks}

In insurance markets with asymmetric information, firms will use what information is available, including information about the amount of insurance purchased, to make inferences about purchasers of insurance. High risk individuals know this, and have an incentive to do what they can to ensure that insurance firms can't tell that they are high risk and to try to keep any relevant information (such as the amount of insurance purchased) secret, and there may be market incentives for firms to comply.

The earlier work of Akerlof and Rothschild-Stiglitz had, of course, shown the importance of the information structure: information about insurance purchased conveyed important information about the individual's type, and therefore, whether that information was available was central in determining the nature of the equilibrium. The differences between Akerlof and RS reflected differences in assumptions about the information structure, e.g. RS assumed sufficient information to enforce exclusivity. Allowing

\footnotetext{
${ }^{70}$ Essentially, this is because area $z$ is never empty, and therefore there always exists a contract that breaks a putative equilibrium.
} 
undisclosed contracts and incorporating realistic assumptions about things that insurance firms know, in particular, that they know the identities of their customers and the quantities purchased, destroys both the RS (quantity constrained) and the Akerlof (price) equilibria.

Expanding the equilibrium construct to include endogenous information disclosure rules is complex, but in fact helps resolve some longstanding conundrums in information economics, in particular the general non-existence of pooling equilibria and the possible non-existence even of a separating equilibrium.

When we endogenize information revelation, the unique equilibrium allocation is a selectively disclosed pooling contract - the pooling contract most preferred by the low risk individual ${ }^{71}$ - plus undisclosed supplemental insurance for just the high risk individuals. The equilibrium contracts endogenously create potential asymmetries in information about insurance purchases that serve as an important deterrent to firms offering contracts that otherwise might break the pooling contract; at least within our framework, such asymmetries are essential to supporting the equilibrium.

In some ways, the equilibrium that arises with endogenous information looks much more like observed phenomena: an equilibrium always exists, and always entails some pooling. Moreover, the analysis and its results do not rely on the highly restrictive single crossing property which has been central in the literature spawned by RS.

The insurance model has proven a useful tool for analyzing more generally markets with asymmetric information, and the papers analyzing imperfect and asymmetric information in that context have led to a huge literature, with the concepts being applied to a rich variety of institutional structures ${ }^{72}$. The natural information assumptions concerning potentially hidden actions and hidden characteristics differ across markets. This paper has raised questions about both the Akerlof and RS analyses, and by implication, the results in the large literature based on them.

We hope that this paper will, like the earlier RS and Akerlof analyses, spawn further research in

\footnotetext{
71 That is, the pooling allocation at the population weighted accident probabilities most preferred by low-risk individuals. In our equilibrium, the contract may be divided up among a number of firms.

72 It is important to recognize that, for the most part, these models of insurance were not intended to provide a good institutional analysis of the insurance market; rather, the insurance market provided the paradigm for studying behavior in, for example, labor, product, and capital markets because it seemed so simple to strip away institutional details, and study markets unencumbered by them. It was for this reason that these paradigmatic models proved so fruitful. The analysis of this paper should be taken in the same spirit.
} 
the context of other markets in the analysis of market equilibrium with asymmetric information where contracts and the information structure/revelation are endogenously and simultaneously determined.

\section{APPENDICES}

\section{Appendix A: Derivations of (2) and (3)}

Assume an individual with a policy $(\alpha, q \alpha)$ supplements it by purchasing $\alpha^{S}(>0)$ at $q_{H}$ to reach full insurance, $\left(\alpha+\alpha^{S}, \mathrm{q} \alpha+q_{H} \alpha^{S}\right)$, where $\mathrm{q} \alpha+q_{H} \alpha^{S}=d-\left(\alpha+\alpha^{S}\right)$. Note that $\alpha^{S}>0$ if $\alpha+q \alpha<\mathrm{d}$. Then

$$
\gamma(\alpha, q \alpha)=\alpha+\alpha^{S}=\frac{1}{1+q_{H}}\left[d+\left(q_{H}-q\right) \alpha\right]
$$

which determines $\delta((\alpha, \alpha q))$ as $B((\alpha, \alpha q))=d-\gamma((\alpha, \alpha q))$. Using (2) and (3), we have

$$
\begin{aligned}
& \mathrm{H}(\alpha, q) \equiv V_{H}(\gamma((\alpha, \alpha q)), \delta((\alpha, \alpha \mathrm{q})))= \\
& =U(W-d+\gamma((\alpha, \alpha q)))=U\left(W+\frac{1}{1+q_{H}}\left[\left(q_{H}-q\right) \alpha-q_{H} d\right]\right),
\end{aligned}
$$

proving Lemma 1.

\section{Appendix B: Proof of Lemma 2}

Consider any set $\left(\alpha_{t}, \beta_{t}\right)_{t}(t=H, L)$ of policies that yield zero profit, i.e.,

$$
\theta \pi_{H}\left(\alpha_{H}, \beta_{H}\right)+(1-\theta) \pi_{L}\left(\alpha_{L}, \beta_{L}\right)=\theta\left\{\left(1-P_{H}\right) \beta_{H}-P_{H} \alpha_{H}\right\}+(1-\theta)\left\{\left(1-P_{L}\right) \beta_{L}-P_{L} \alpha_{L}\right\}=0
$$

Let each policy $\left(\alpha_{t}, \beta_{t}\right)$ be represented as the sum of $\left(\hat{\alpha}_{t}, \hat{\beta}_{t}\right)$ and $\left(\alpha_{t}^{S}, \beta_{t}^{S}\right)$, where

$$
\alpha_{\mathrm{t}}=\hat{\alpha}_{\mathrm{t}}+\alpha_{t}^{S}, \beta_{\mathrm{t}}=\widehat{\beta}_{\mathrm{t}}+\beta_{t}^{S} \text { while } \hat{\beta}_{\mathrm{t}}=\bar{q} \hat{\alpha}_{\mathrm{t}}, \quad \beta_{t}^{S}=q_{t} \alpha_{t}^{S}
$$

It will then suffice to show that $\hat{\alpha}_{\mathrm{H}}=\hat{\alpha}_{\mathrm{L}}$. Since $\pi_{t}\left(\alpha_{t}^{S}, \beta_{t}^{S}\right)=0$ for $t=H, L$ we have

$$
\theta \pi_{H}\left(\hat{\alpha}_{\mathrm{H}}, \hat{\beta}_{\mathrm{H}}\right)+(1-\theta) \pi_{L}\left(\hat{\alpha}_{\mathrm{L}}, \hat{\beta}_{\mathrm{L}}\right)=0 .
$$

Using $\bar{\beta}_{\mathrm{t}}=\bar{q} \hat{\alpha}_{\mathrm{t}}$ and rearranging the terms, we have

$$
\theta\left[\bar{P}-P_{H}\right] \hat{\alpha}_{\mathrm{H}}+(1-\theta)\left[\bar{P}-P_{L}\right] \hat{\alpha}_{\mathrm{L}}=0 .
$$


Using the result that $\theta\left[\bar{P}-P_{H}\right]+(1-\theta)\left[\bar{P}-P_{L}\right]=0$, this implies that

$$
\theta\left[\bar{P}-P_{H}\right]\left(\hat{\alpha}_{\mathrm{H}}-\hat{\alpha}_{\mathrm{L}}\right)=0
$$

i.e., $\hat{\alpha}_{\mathrm{H}}=\hat{\alpha}_{\mathrm{L}}$.

\section{Appendix C: Proof of Lemma 5}

Given the equilibrium contract, a consumer purchasing more than $\bar{\alpha}$ must not reveal his full purchases to any firm. Assume a consumer purchases more than $\bar{\alpha}$ from $\mathrm{K}$ firms, and suppose the consumer makes any set of disclosures. Pick up first the firm that is the most informed (by the consumer) ${ }^{73}$, say firm $j_{1}(<\mathrm{K})$, who knows about the consumer's purchases from firms $1,---, j_{1}$ (including his own sales) and does not know about his purchases from firms $j_{1}+1,--, \mathrm{K}$, a group of firms undisclosed to $j_{1}$. (When there is a tie in which firm is the most informed, choose any of those; $j_{1}=1$ if a consumer does not disclose anything to any firm). Focus then upon the firms $\left(j_{1}+1,--, K\right)$ undisclosed to $j_{1}$, and consider a firm who is the most informed of the purchases from those firms, say $j_{2}$, who knows about the purchases from $j_{1}+1,--$, $j_{2}$. Similarly, we consider the most informed of the firms undisclosed to $j_{2}$ and $j_{1}$, say $j_{3}$. We can continue until we get $j_{k}$, where $j_{k}=K$. Then, clearly, the purchase from firm $j_{k}$ is undisclosed to firms $j_{1}, j_{2},--, j_{k-1}$.

Now consider the disclosures by firms. As a firm discloses to any other firm that is undisclosed by the consumer as his insurer, all the firms $j_{1}, j_{2},--, j_{k-1}$ (at least) will disclose to the firm $j_{k}$ their own sales and information received from the consumer, implying that the firm $j_{k}$ knows all of the $\mathrm{K}$ purchases. ${ }^{74}$

\section{Appendix D: A summary of the notation}

- Policies Purchased (by individual i)

$x(j)$ : policy purchased from firm $j$

$\widehat{X}$ : set of all policies purchased

- Consumer Disclosure

\footnotetext{
${ }^{73}$ By most informed, we simply mean the number of contracts that have been disclosed.

${ }^{74}$ It is trivial that this procedure works in the example given in the text, where the individual purchases $1 / 2 \bar{\alpha}$ from $A$, $B$, and $C$, disclosing its sales to $B$ to $A$, to $C$ to $B$, and to $A$ to $C$. All are equally informed. $A$ then knows about its own sales and that of $B$, and discloses this information to $C$, who then knows about $A, B$, and C's sales, who then cancels its policy.
} 
$X_{j}^{o-\mathrm{j}}$ : set of consumer-revealed purchases to $\mathrm{j}$

$I$ : set of consumer-revealed insurers

- Firm Disclosure

$R E_{j}$ : set of firms receiving information from firm $\mathrm{j}$

$I N F_{j k}:$ information disclosed by firm $j$ to firm $k$

- Aggregate Information

$X_{j}^{o}$ : union of information revealed to firm $\mathrm{j}$ by consumers and his own information: $X_{j}^{o} \equiv$ $\mathrm{x}(\mathrm{j}) \cup X_{j}^{o-\mathrm{j}}$

$X_{j}^{T}$ : total information about consumer i's purchases available to firm $j$.

\section{References}

Akerlof, George A. (1970), "The market for 'lemons': Quality Uncertainty and the Market Mechanism," Quarterly Journal of Economics, 84(3), pp. 488-500.

Ales, Laurence and Pricila Maziero (2012), "Adverse Selection and Non-exclusive Contracts," Working Paper, Carnegie Mellon University.

Arnott, Richard J. and Joseph E. Stiglitz (1987, 2013), "Equilibrium in competitive insurance markets with moral hazard." in The Selected Works of Joseph E. Stiglitz, Volume II: Information and Economic Analysis: Applications to Capital, Labor, and Product Markets, Oxford: Oxford University Press, 2013, pp. 660- 689. Edited version of Princeton University Discussion Paper 4, 1987

Arnott, Richard J. and Joseph E. Stiglitz (1991, 2013), "Price Equilibrium, Efficiency, and Decentralizability in Insurance Markets," in The Selected Works of Joseph E. Stiglitz, Volume II: Information and Economic Analysis: Applications to Capital, Labor, and Product Markets, Oxford: Oxford University Press, 2013, pp. 632-659. Edited version of NBER Working Paper 3642, 1991.

Attar, Andrea, Thomas Mariotti, and François Salanié (2011), "Nonexclusive competition in the market for lemons," Econometrica, 79(6), 1869-1918.

Attar, Andrea, Thomas Mariotti, and François Salanié (2014), "Nonexclusive Competition under Adverse Selection," Theoretical Economics, 9(1), pp. 1-40.

Attar, Andrea, Thomas Mariotti, and François Salanié (2016), "Multiple Contracting in Insurance Markets," Working Paper, TSE-532.

Dasgupta, Partha and Eric Maskin (1986), "The Existence of Equilibrium in Discontinuous Games: I," Review of Economic Studies, 53(1), pp. 1-26. 
Glosten, L.R. (1994), “Is the Electronic Open Limit Order Book Inevitable?” Journal of Finance, 49(4), 11271161

Greenwald, Bruce (1979), Adverse Selection in the Labor Market, Routledge: New York.

Greenwald, Bruce (1986), "Adverse Selection in the Labor Market," The Review of Economic Studies, Volume 53, Issue 3, p. 325

Greenwald, Bruce, J. E. Stiglitz, and A. Weiss (1984), "Informational Imperfections in the Capital Markets and Macroeconomic Fluctuations," American Economic Review, 74(2), May 1984, pp. 194-199

Greenwald, Bruce and J. E. Stiglitz (1986), "Externalities in Economies with Imperfect Information and Incomplete Markets," Quarterly Journal of Economics, 101(2), pp. 229-264.

Hellwig, Martin F. (1987), "Some Recent Developments in the Theory of Competition in Markets with Adverse Selection," European Economic Review, 31(1-2), pp. 309-325.

Hellwig, Martin F. (1988), "A note on the specification of interfirm communication in insurance markets with adverse selection," Journal of Economic Theory, 46(1), pp. 154-163.

Holmström, B., \& Myerson, R. (1983). Efficient and Durable Decision Rules with Incomplete Information. Econometrica, 51(6), 1799-1819.

Jaynes, Gerald D. (1978), "Equilibria in monopolistically competitive insurance markets," Journal of Economic Theory, 19(2), pp. 394-422.

Jaynes, Gerald D. (2011), "Equilibrium and Strategic Communication in the Adverse Selection Insurance Model," Working Paper, Yale University.

Jaynes, Gerald D. (2018), "Endogenous Beliefs and Institutional Structure in Competitive Equilibrium with Adverse Selection". Working Paper, Yale University.

Mirrlees, J. (1971). "An Exploration in the Theory of Optimum Income Taxation." The Review of Economic Studies, 38(2), 175-208.

Riley, John (1979), “Informational Equilibrium,” Econometrica, 47(2), pp. 331-359.

Rothschild, Michael and Joseph E. Stiglitz (1976), "Equilibrium in competitive insurance markets: An essay on the economics of imperfect information," Quarterly Journal of Economics, 90, pp. 629-649.

Rothschild, Michael and Joseph E. Stiglitz (1997), "Competition and Insurance Twenty Years Later," Geneva Papers on Risk and Insurance Theory, 22(2), pp. 73-79.

Spence, M. (1973). “Job Market Signaling.” The Quarterly Journal of Economics, 87(3), 355-374.

Stiglitz, Joseph E. (1977), "Monopoly, Non-Linear Pricing and Imperfect Information: The Insurance Market," Review of Economic Studies, 44(3), pp. 407-430.

Stiglitz, Joseph E (2009), "Introduction to Part IIB," in Selected Works of Joseph E. Stiglitz, Volume I: Information and Economic Analysis, Oxford: Oxford University Press, 2009, pp. 129-140. 
Stiglitz, Joseph and J. Yun (2016), "Equilibrium in a Competitive Insurance Market with Non-exclusivity Under Adverse Selection," mimeo.

Stiglitz, Joseph, Jungyoll Yun, and Andrew Kosenko (2018) "Characterization, Existence, and Pareto Optimality in Insurance Markets with Asymmetric Information with Endogenous and Asymmetric Disclosures: Revisiting Rothschild-Stiglitz," (update and revision of "Equilibrium in a Competitive Insurance Market Under Adverse Selection with Endogenous Information", NBER Working Paper No. w23556, 4 Jul 2017), NBER Working Paper No. 24711, June

Wilson, C. (1977), "A model of insurance markets with incomplete information," Journal of Economic Theory, 16(2), pp. 167-207.

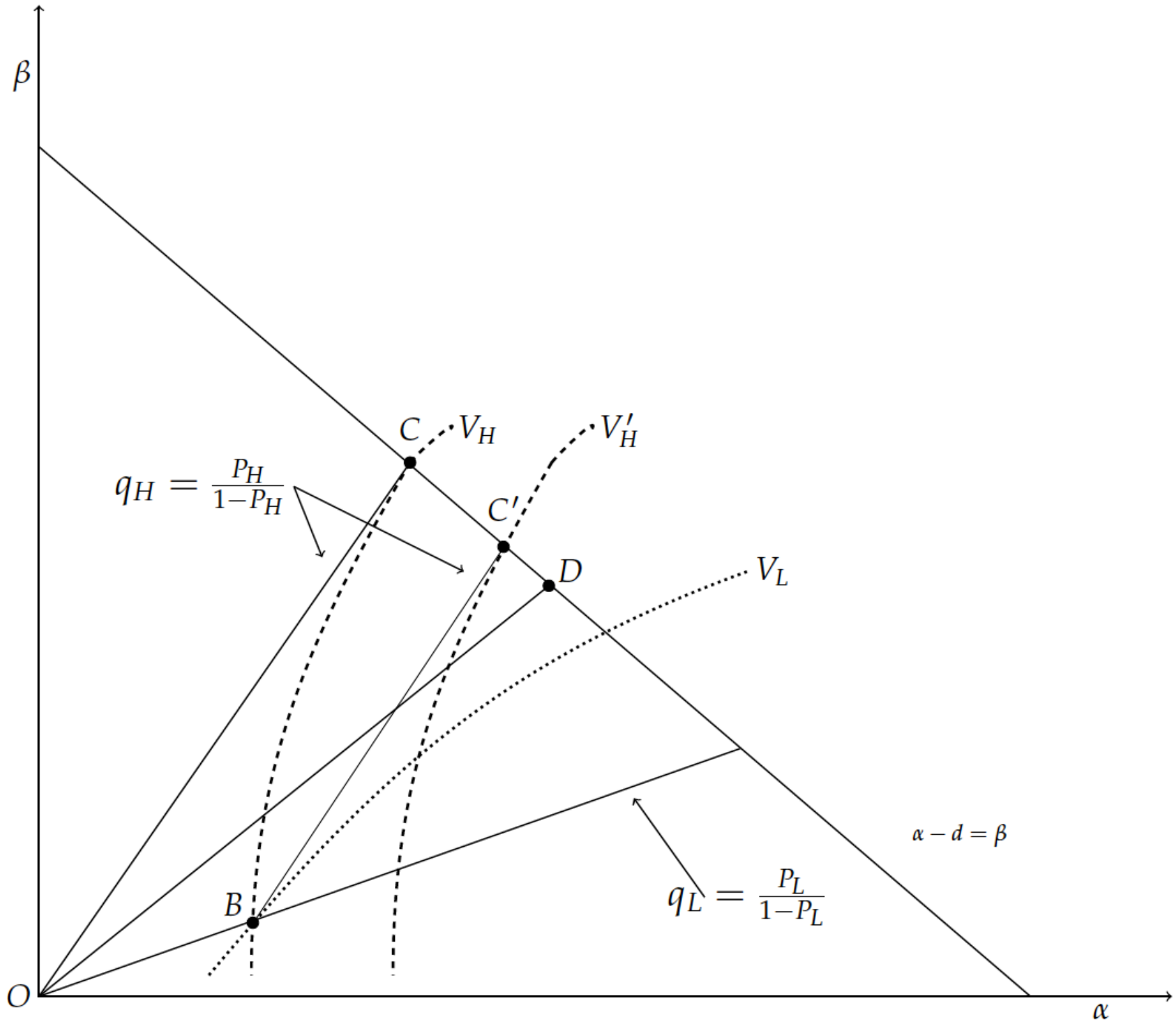

Figure 1: Breaking the RS separating equilibrium $(B, C)$ in the presence of undisclosed contracts at high-risk odds. 


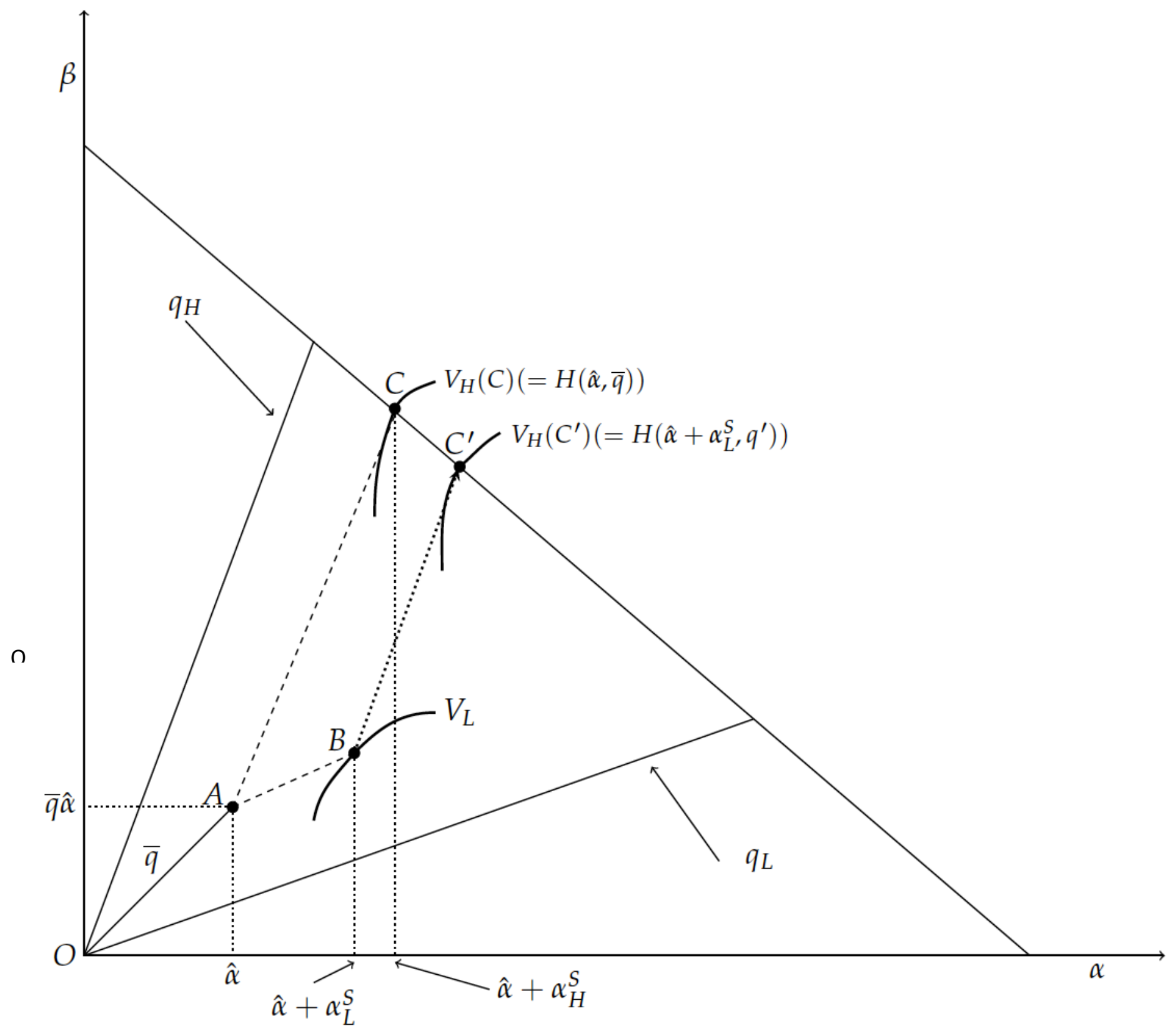

Figure 2: An allocation $(B, C)$ can be decomposed as $A$ and $(A C, A B)$. Allocation $(B, C)$ is not feasible as it does not satisfy the self-selection constraints in the presence of undisclosed policies at high-risk odds $q_{H}$, while $(A, C)$ is a feasible one; $q^{\prime}=$ slope of $O B(<\bar{q})$. 


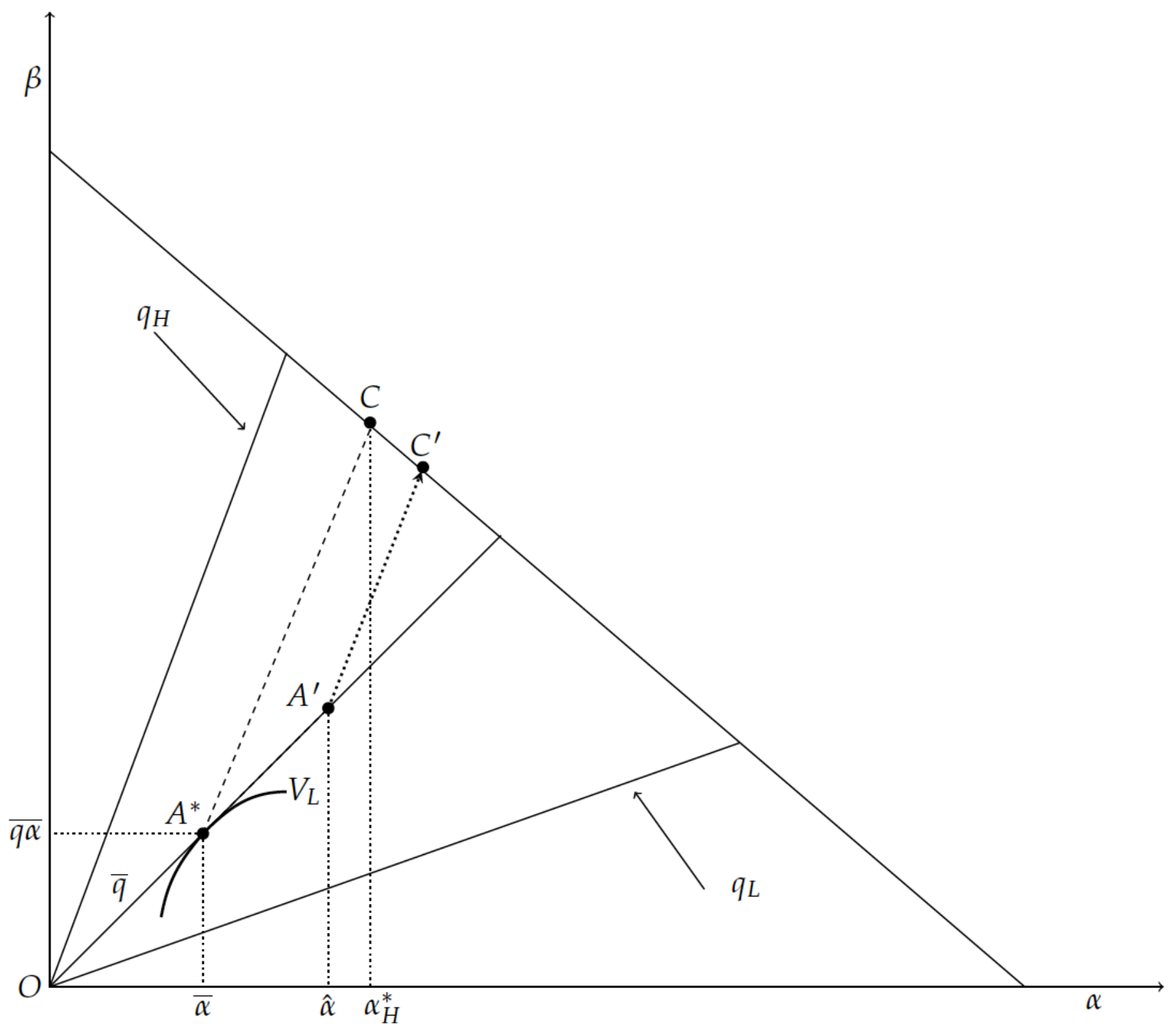

Figure 3: Pareto Efficient Allocations $\left\{Z_{t}(\hat{\alpha})\right\}_{t}$, denoted by $\left(A^{\prime}, C^{\prime}\right)$, and the equilibrium allocation $\left\{Z_{t}(\bar{\alpha})\right\}$ denoted by $\left(A^{*}, C\right)$ 


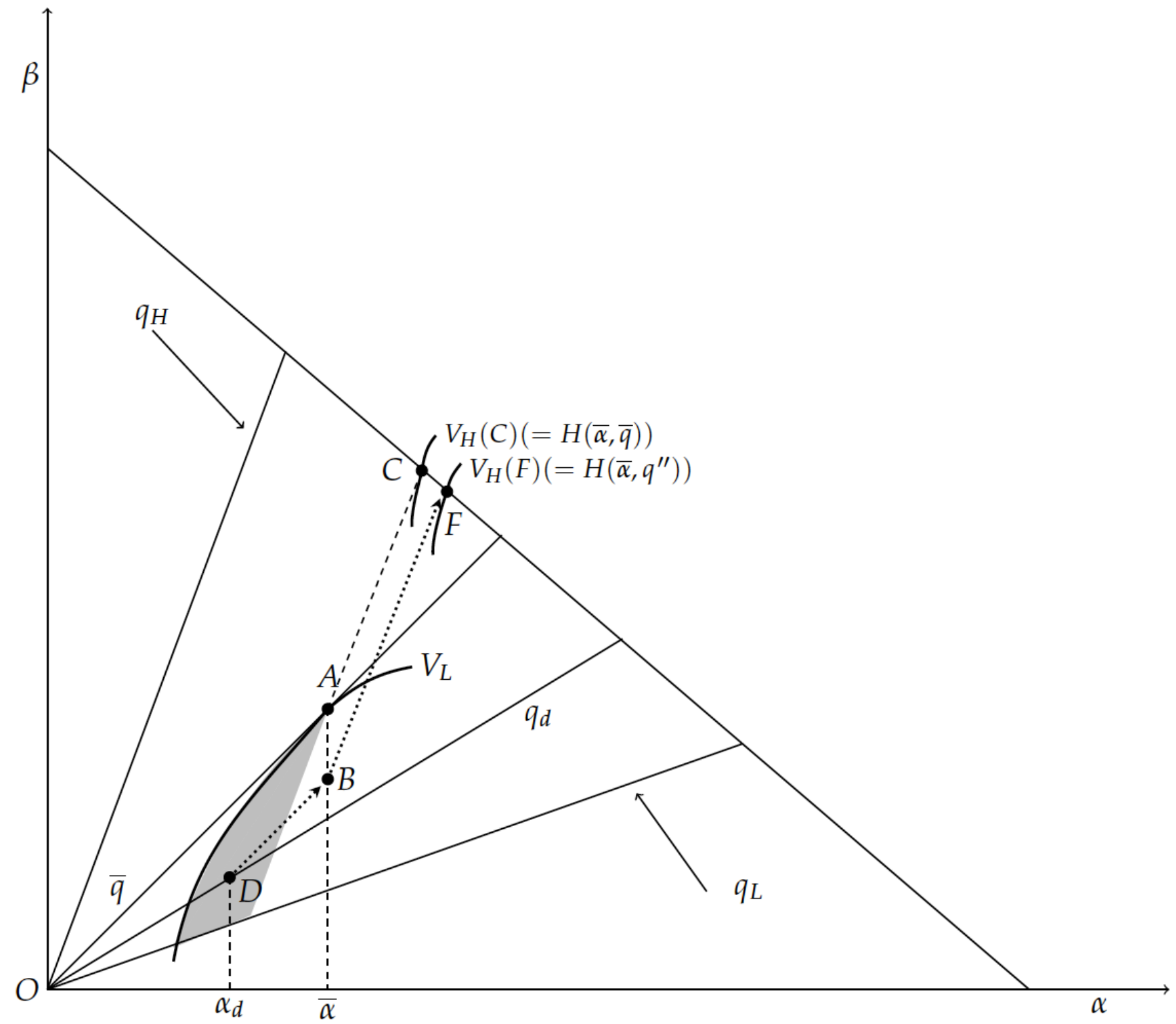

Figure 4: Sustaining an equilibrium against $C_{d}$ (offering $D$ ); $q^{\prime \prime}=$ slope of $O B(<\bar{q})$. High risk individuals would always supplement $D$ with pooling insurance $(D B)$ (disclosed only to non-deviant established firms) and secret insurance $(B F)$. As a result $V_{H}(F)>V_{H}(C)$, and accordingly, the deviant contract would make losses. 


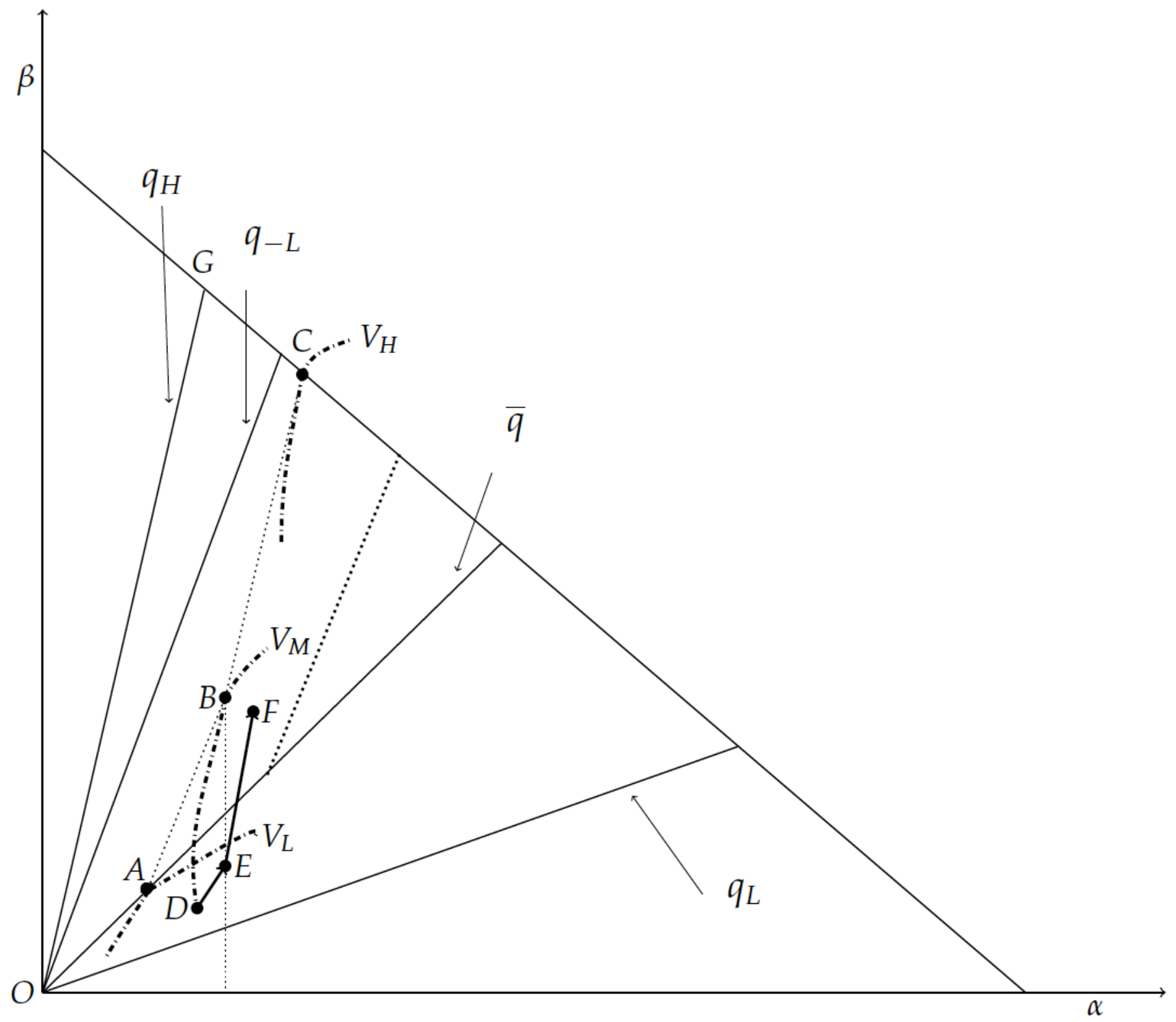

Figure 5: Equilibrium $(A, B, C)$ with three types, which cannot be broken by $D$ as individuals of higherrisk type supplement it by additional pooling insurance (along the arrow) without being disclosed to the deviant firm. The slopes of the various lines are indicated by the $q$ 's. $P_{-L}$ denotes the average probability of accident for the two highest risk types (and $q_{-L}=\frac{P_{-L}}{1-p_{-L}}$ ), while $V_{i}$ indicates an indifference curve for $i$-risk type $(i=H, M, L)$. The lines $A B$ and $D E$ are parallel to $O C$; the lines $E F$ and $B C$ are parallel to $O G$. We illustrate this with only the highest-risk type, but the statement is also true of the intermediate type(s). 